\title{
Facile and Divergent Optimization of Chromazonarol Enabled the Identification of Simplified Drimane Meroterpenoids as Novel Pharmaceutical Leads
}

\author{
Xia Wang ${ }^{1,2}, \mathrm{Nvdan}_{\mathrm{Hu}^{1}}$, Wenlong Kong ${ }^{1}$, Baoan Song ${ }^{1}$, Shengkun Li*,1,2 \\ ${ }^{1}$ Laboratory Breeding Base of Green Pesticide and Agricultural Bioengineering, Key Laboratory of Green Pesticide and Agricultural Bioen- \\ gineering, Ministry of Education, Guizhou University, Huaxi District, Guiyang 550025, China \\ ${ }^{2}$ Department of Pesticide Science, College of Plant Protection, Nanjing Agricultural University, Weigang 1, Xuanwu District, Nanjing 210095, \\ People's Republic of China.
}

Received (date)**; accepted (date) **;

\begin{abstract}
The coverage of drimane hydroquinones chemical space was expanded by the facile construction of the focused libraries of $(+)$-chromazonarol relevant natural products, isomers and analogues for advance as pharmaceutical leads. Through the synergistic interaction of the programmable synthesis and bioactivity-guided screening, the structure-activity relationship of $(+)-$ chromazonarol relevant (non)-natural products was delineated. The first divergent derivatization of (+)-chromazonarol demonstrated that the phenolic hydroxyl group is one inviolable requirement for antifungal effect. Pinpoint modification of $(+)-$ yahazunol manifested the position of hydroxyl group was crucial for both antifungal and antitumor activities. $(+)$-Albaconol, $(+)$-neoalbaconol and two yahazunol isomers $(\mathbf{2 4}$ and $\mathbf{2 5})$ were witnessed to be the novel pharmaceutical leads. The probable macromolecular targets were estimated to deliver new information about the biological potential resident in $(+)$-yahazunol relevant products. This work also featured the first synthesis of $(+)$-albaconol and $(+)$-neoalbaconol, the first biological exploration of $(+)$-dictyvaric acid and an improved preparation of $(+)-8$-epi-puupehedione and a promising pelorol analogue.
\end{abstract}

Drimane meroterpenoids, divergent synthesis, structure-activity relationship, pharmaceutical leads, Suzuki coupling

\section{Introduction}

The accumulated evolutionary wisdom endows natural products with novel and diverse scaffolds and activities, which demonstrated an unparalleled valuable significance for the discovery of pharmaceutically important molecules, including both drugs and agrochemicals [1-5]. Either the natural scarcity or the structural complexity often hampers further optimization and investigation of potential natural products in the discovery pipeline of pharmaceutical candidates. This situation became more serious in the basic research of complex natural products as leads or probes for the discovery of new agrochemicals. Among the manifold and involute drimane meroterpenoids, the drimane (hy-

*Corresponding authors (email: SKL505@outlook.com) dro)quinones (Figure 1A), biosynthetically arising from the union of drimane-type terpenoids with phenols or the corresponding oxidized segments [6], are a large family of secondary metabolites with various bioactivities. The constant characteristic assembling Csp3 hybridized skeleton with Csp2 hybridized aromatic units showed great pharmaceutical potentials.

The agrochemical potentials were still underexplored and only sporadic reports were disclosed about this kind of natural metabolites. Interestingly, some structurally simple natural products in this category, including (-)-yahazunol, zonarol, isozonarol, zonarone, and isozonarone, were isolated and reported to show moderate antifungal effect against Phytophthora cinnamomic, Rhizoctonia solani, and Sclerotinia sclerotiorum. [7] Both (+)-Chromazonarol and its enantiomer occurred naturally as the ring formed congeners of yahazunol and demonstrated interesting biological poten- 
tials [8-14]. Alongside the unique scaffold and various bioactivities, these natural products possessed an irreplaceable role in target identification, e.g. siccanin was reported to target succinate dehydrogenase [15].

With the continuing interests in the discovery of new antifungal agrochemicals, our basic research was inspired by not only the classical amide fungicides [16-18], but also the structurally different drimane hydroquinones and drug-like analogues [19-22]. Recently, we showcased the potential of (+)-chromazonarol as a novel antifungal scaffold [22], which is unique in agrochemical industry from the standpoint of structural analysis. Any progress in the synthesis of focused libraries of $(+)$-chromazonarol will expand the cov- erage of chemical space with favorable properties for advance as pharmaceutical leads. To the best of our knowledge, (+)-chromazonarol or its enantiomer was just products from bioactivity-guided isolation (vide supra) or used as a synthetic hub for the target-oriented synthesis of related natural products [22-26] (Figure 1B). We interrogate that the divergent optimization of $(+)$-chromazonarol may facilitate the discovery of new pharmaceutical leads. Modular and practical synthesis of this natural product is desirable and will be powerful to solve the challenging supply of ample materials. This can spark specific works to make and explore structures that were previously inaccessible.

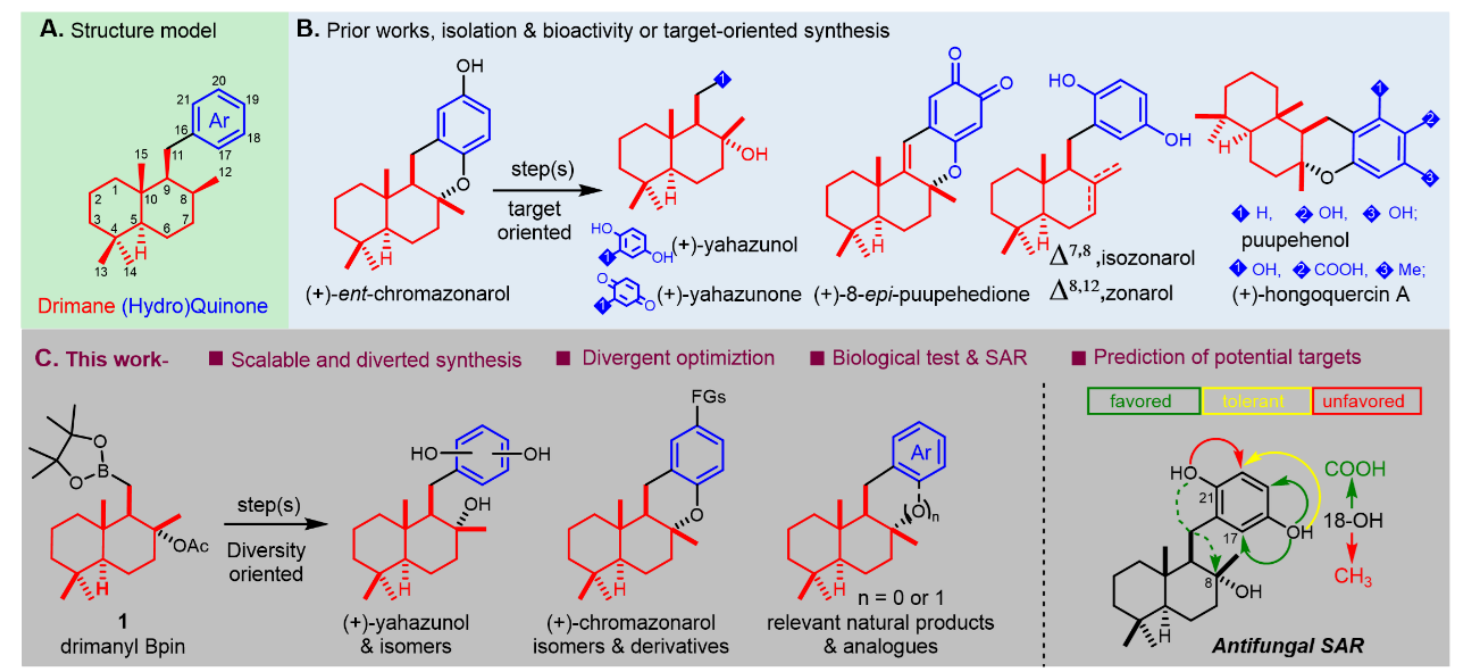

Figure 1 progress in chromazonarol relevant drimane hydroquinones and this work.

In terms of project design, we would like to document the unprecedented function-oriented divergent optimization of chromazonarol through facile and programmable $\mathrm{C}(\mathrm{sp} 3)-$ $\mathrm{C}(\mathrm{sp} 2)$ coupling for monitoring the pharmaceutical potentials and structure and activity relationship (SAR). Structurally complicated and simplified (+)-chromazonarol derivatives and (non)-natural analogues will be discussed (Figure 1C). The unprecedented yahazunol relevant natural products and isomers will be estimated as ideal models for the development of novel class of antifungal or antitumor agents. The probable macromolecular targets will be predicted to deliver new information about the biological potential. Buoyed by these success, the first synthesis and antifungal profiles of $(+)$-albaconol and $(+)$-neoalbaconol, the first biological profiles and improved synthesis of (+)-dictyvaric acid, and an improved preparation of (+)-8-epi-puupehedione and a promising pelorol analogue will also be disclosed.

\section{Experimental}

\subsubsection{Synthesis of compound 2}

To a stirred solution of the 2-bromobenzene-1,4-diol (187 mg, 1.00 mmol, 1.0 equiv.) and $\mathrm{K}_{2} \mathrm{CO}_{3}(245 \mathrm{mg}, 2.50 \mathrm{mmol}$, 2.5 equiv.) in DMF $(5.0 \mathrm{~mL})$ was added benzyl bromide (296 $\mu \mathrm{L}, 2.5 \mathrm{mmol}, 2.5$ equiv.) at rt. The resultant mixture was stirred at $90{ }^{\circ} \mathrm{C}$ over night before it was quenched with saturated aq. $\mathrm{NH}_{4} \mathrm{Cl}(10.0 \mathrm{~mL})$ and extracted with EtOAc (3 $\times 10 \mathrm{~mL}$ ). The combined organic phases were washed with water and brine $(10 \mathrm{~mL})$, dried over anhydrous $\mathrm{Na}_{2} \mathrm{SO}_{4}$, filtered, and concentrated under vacuum. The residue was purified by column chromatography on silica gel (200-300 $\mathrm{m})$ with petroleum ether/EtOAc $(\mathrm{v} / \mathrm{v}, 5 / 1)$ as the eluent gave the product 2 (white solid, $260 \mathrm{mg}, 70 \%$ ). ${ }^{1} \mathrm{H}$ NMR (400 $\left.\mathrm{MHz}, \mathrm{CDCl}_{3}\right) \delta 7.50-7.43(\mathrm{~m}, 2 \mathrm{H}), 7.43-7.30(\mathrm{~m}, 8 \mathrm{H})$, $7.24(\mathrm{~d}, J=2.5 \mathrm{~Hz}, 1 \mathrm{H}), 6.89-6.82(\mathrm{~m}, 2 \mathrm{H}), 5.09(\mathrm{~s}, 2 \mathrm{H})$, $5.00(\mathrm{~s}, 2 \mathrm{H}) .{ }^{13} \mathrm{C}$ NMR $\left(101 \mathrm{MHz}, \mathrm{CDCl}_{3}\right) \delta 153.51,149.57$, $136.78,136.65,128.65$ (2C), 128.56 (2C), 128.12, 127.94, 127.53 (2C), 127.19 (2C), 120.04, 115.33, 114.63, 113.11, $71.80,70.77$. All spectral data matches that of previously reported.

\subsubsection{Synthesis of compound $\mathbf{3}$}

To a schlenck flask equipped with a stir bar, $\operatorname{Pd}_{2}(\mathrm{dba})_{3}(2$ mol\%), NaOtBu (4 equiv.), Ruphos (4 mol\%), the drimanyl Bpin 1 (1.2 equiv.) and 2 (0.25 mmol, 1.0 equiv.) were add- 
ed sequentially. The tube was evacuated and filled with $\mathrm{N}_{2}$ (three cycles). tert-Butanol $(1.0 \mathrm{~mL}), \mathrm{H}_{2} \mathrm{O}(0.1 \mathrm{~mL})$ were added in turn by syringe under an $\mathrm{N}_{2}$ atmosphere. The resulting reaction mixture was stirred vigorously at $100{ }^{\circ} \mathrm{C}$ metal heating mantle for $18 \mathrm{~h}$. The reaction mixture was then diluted with EtOAc $(5 \mathrm{~mL})$, the reaction mixture was sequentially washed with water $(5 \mathrm{~mL})$ and saturated aqueous $\mathrm{NaCl}(5 \mathrm{~mL})$, dried over anhydrous sodium sulfate, and concentrated under vacuum. Purification by silica gel column chromatography on silica gel (200-300 m) with petroleum ether/EtOAc with petroleum ether/EtOAc (5:1, v/v) as the eluent gave the product $3(111 \mathrm{mg}, 87 \%$, light yellow oil). ${ }^{1} \mathrm{H}$ NMR (500 MHz, $\left.\mathrm{CDCl}_{3}\right) \delta 7.51-7.28(\mathrm{~m}, 10 \mathrm{H})$, $6.88(\mathrm{~s}, 1 \mathrm{H}), 6.82(\mathrm{~d}, J=8.6 \mathrm{~Hz}, 1 \mathrm{H}), 6.72(\mathrm{~d}, J=8.6 \mathrm{~Hz}$, $1 \mathrm{H}), 5.03-4.92(\mathrm{~m}, 4 \mathrm{H}), 2.80(\mathrm{dd}, J=14.5,5.1 \mathrm{~Hz}, 1 \mathrm{H})$, $2.58(\mathrm{~d}, J=14.5 \mathrm{~Hz}, 1 \mathrm{H}), 1.79-1.69(\mathrm{~m}, 2 \mathrm{H}), 1.61-1.45$ $(\mathrm{m}, 4 \mathrm{H}), 1.37-1.27(\mathrm{~m}, 3 \mathrm{H}), 1.26-1.19(\mathrm{~m}, 1 \mathrm{H}), 1.15(\mathrm{~s}$, $3 \mathrm{H}), 1.13-1.03(\mathrm{~m}, 1 \mathrm{H}), 0.89-0.86(\mathrm{~m}, 1 \mathrm{H}), 0.85(\mathrm{~s}, 3 \mathrm{H})$, $0.83(\mathrm{~s}, 3 \mathrm{H}), 0.77(\mathrm{~s}, 3 \mathrm{H}), 0.76-0.72(\mathrm{~m}, 1 \mathrm{H}) .{ }^{13} \mathrm{C} \mathrm{NMR}$ $\left(126 \mathrm{MHz}, \mathrm{CDCl}_{3}\right): \delta 153.2,150.3,137.4,136.8,134.6$, 128.6 (2C), 128.6 (2C), 128.2, 128.1 (2C), 127.9, 127.6 (2C), 118.2, 113.1, 111.8, 73.8, 71.3, 70.5, 62.5, 56.1, 43.4, $41.8,40.2,39.2,33.5,33.3,25.0,24.3,21.6,20.2,18.6$, 15.4 .

\subsubsection{Synthesis of (+)-yahazunol 4}

To a stirred solution of the 3 (103 $\mathrm{mg}, 0.2 \mathrm{mmol}, 1.0$ equiv.) and ammonium formate (253 mg, $4.00 \mathrm{mmol}, 20.0$ equiv.) in $\mathrm{MeOH}(5.0 \mathrm{~mL})$ was added $\mathrm{Pd} / \mathrm{C}(5 \%, 174 \mathrm{mg}, 1.6$ mmol, 8.0 equiv.) at rt. The resultant mixture was stirred and heated at reflux temperature overnight. After the complete disappearance of the $\mathbf{3}$ (monitored by TLC), the reaction mixture was cooled to $\mathrm{rt}$ and filtered. The filtrate was washed twice with $\mathrm{MeOH}$. Evaporation of the solvent under reduced pressure and subsequent chromatography on silica gel $(200-300 \mathrm{~m})$ with petroleum ether/EtOAc $(5: 1, \mathrm{v} / \mathrm{v})$ as the eluent gave the $(+)$-yahazunol $4(51 \mathrm{mg}, 77 \%$, off-white solid). ${ }^{1} \mathrm{H}$ NMR $\left(500 \mathrm{MHz}\right.$, Acetone- $\left.d_{6}\right) \delta 8.78(\mathrm{~s}, 1 \mathrm{H}), 7.46$ $(\mathrm{s}, 1 \mathrm{H}), 6.63(\mathrm{~d}, J=2.8 \mathrm{~Hz}, 1 \mathrm{H}), 6.54-6.47(\mathrm{~m}, 2 \mathrm{H}), 4.92$ (s, 1H), 2.84 (dd, $J=15.0,2.3 \mathrm{~Hz}, 1 \mathrm{H}), 2.39$ (dd, $J=15.0$, $6.2 \mathrm{~Hz}, 1 \mathrm{H}), 1.97-1.86(\mathrm{~m}, 1 \mathrm{H}), 1.88-1.78(\mathrm{~m}, 1 \mathrm{H}), 1.70$ -1.54 (m, 4H), $1.41-1.30(\mathrm{~m}, 3 \mathrm{H}), 1.29$ (s, 3H), 1.10 (td, $J$ $=13.6,13.1,4.3 \mathrm{~Hz}, 1 \mathrm{H}), 0.98-0.93(\mathrm{~m}, 4 \mathrm{H}(\mathrm{s}, 0.97)), 0.85$ $(\mathrm{s}, 3 \mathrm{H}), 0.82(\mathrm{~s}, 3 \mathrm{H}), 0.71(\mathrm{td}, J=13.2,3.7 \mathrm{~Hz}, 1 \mathrm{H}) .{ }^{13} \mathrm{C}$ NMR $\left(126 \mathrm{MHz}\right.$, Acetone- $\left.d_{6}\right) \delta 150.71,150.12,131.48$, 119.26, 117.83, 114.67, 75.51, 62.64, 57.28, 44.88, 42.87, $41.73,40.93,34.19,34.14,28.35,24.92,22.21,21.51$, $19.41,16.25$. All spectral data matches that of the isolated natural product.

\subsubsection{Synthesis of $(+)$-chromazonarol 5}

To a solution of (+)-yahazunol 4 (146 mg, $0.45 \mathrm{mmol})$ in anhydrous $\mathrm{CH}_{2} \mathrm{Cl}_{2}(5 \mathrm{~mL})$ was added TFA $(35.00 \mu \mathrm{L}, 0.45$ mmol) at ambient temperature. The reaction mixture was stirred until full conversion as monitored by TLC. A saturated $\mathrm{Na}_{2} \mathrm{CO}_{3}$ aqueous solution $(10 \mathrm{~mL})$ was added to quench the reaction. The separated aqueous phase was extracted with $\mathrm{CH}_{2} \mathrm{Cl}_{2}(3 \times 10 \mathrm{~mL})$. The combined organic phases were washed with $\mathrm{H}_{2} \mathrm{O}(10 \mathrm{~mL})$ and brine $(10 \mathrm{~mL})$, dried over anhydrous $\mathrm{Na}_{2} \mathrm{SO}_{4}$, filtered, and concentrated under reduced pressure. The resultant residue was purified by chromatography on silica gel $(200-300 \mathrm{~m})$ with petroleum ether/EtOAc $(8: 1, \mathrm{v} / \mathrm{v})$ as the eluent gave the $(+)-$ chromazonarol 5 (127 mg, $91 \%$, white solid). ${ }^{1} \mathrm{H}$ NMR $\left(500 \mathrm{MHz}, \mathrm{CDCl}_{3}\right) \delta 6.63(\mathrm{~d}, J=8.5 \mathrm{~Hz}, 1 \mathrm{H}), 6.58-6.54$ $(\mathrm{m}, 2 \mathrm{H}), 4.97(\mathrm{br}, 1 \mathrm{H}), 2.59-2.51(\mathrm{~m}, 2 \mathrm{H}), 2.07-2.02(\mathrm{~m}$, $1 \mathrm{H}), 1.78-1.71(\mathrm{~m}, 1 \mathrm{H}), 1.70-1.59(\mathrm{~m}, 4 \mathrm{H}), 1.53-1.41$ (m, 1H), $1.40-1.30(\mathrm{~m}, 2 \mathrm{H}), 1.19-1.12(\mathrm{~m}, 4 \mathrm{H}(\mathrm{s}, 1.17))$, 1.02 (dd, $J=12.1,2.3 \mathrm{~Hz}, 1 \mathrm{H}), 0.98-0.93(\mathrm{~m}, 1 \mathrm{H}), 0.90$ (s, $3 \mathrm{H}), 0.87(\mathrm{~s}, 3 \mathrm{H}), 0.84(\mathrm{~s}, 3 \mathrm{H}) .{ }^{13} \mathrm{C} \mathrm{NMR}\left(126 \mathrm{MHz}, \mathrm{CDCl}_{3}\right)$ $\delta 148.78,147.16,123.49,117.67,116.01,114.42,56.26$, $52.20,41.98,41.25,39.33,36.96,33.62,33.37,27.10$, $22.66,21.80,20.86,19.92,18.70,15.03$. All spectral data matches that of the isolated natural product.

2.2.1 General procedure for synthesis etherified derivatives (6a $\sim \mathbf{6 g})$ of $(+)$-chromazonarol

To a stirred solution of (+)-chromazonarol (62 mg, 0.2 $\mathrm{mmol})$ in anhydrous THF $(10 \mathrm{~mL})$ were added sodium hydrogen $(\mathrm{NaH})(22 \mathrm{mg}, 0.9 \mathrm{mmol}, 4.5 \mathrm{eq})$ and iodomethane (75 $\mu \mathrm{L}, 1.5 \mathrm{mmol}$ ) dropwise at $0{ }^{\circ} \mathrm{C}$. Subsequently, the mixture was stirred and the system gradually raised to room temperature. The reaction progress was monitored by TLC until the reaction was complete $(\sim 5 \mathrm{~h})$. The solvent was removed under reduced pressure, and the residue was added a saturated aqueous solution of $\mathrm{NH}_{4} \mathrm{Cl}(10 \mathrm{~mL})$ and $\mathrm{CH}_{2} \mathrm{Cl}_{2}$ $(10 \mathrm{~mL})$. The organic layer was separated, and the aqueous phase was extracted with $\mathrm{CH}_{2} \mathrm{Cl}_{2}(2 \times 10 \mathrm{~mL})$. The combined organic layers were washed with brin $(10 \mathrm{~mL})$, dried over $\mathrm{Na}_{2} \mathrm{SO}_{4}$, and concentrated. The residue was purified by flash chromatography (200-300 mesh) with PE/EtOAc = 20:1 (v/v) as eluent to give the compound 6a (64 mg, $98 \%$, white solid). ${ }^{1} \mathrm{H}$ NMR $\left(400 \mathrm{MHz}, \mathrm{CDCl}_{3}\right) \delta 6.70-6.65(\mathrm{~m}$, $2 \mathrm{H}), 6.61(\mathrm{~d}, J=2.2 \mathrm{~Hz}, 1 \mathrm{H}), 3.74(\mathrm{~s}, 3 \mathrm{H}), 2.64-2.54(\mathrm{~m}$, $2 \mathrm{H}), 2.08-2.01(\mathrm{~m}, 1 \mathrm{H}), 1.80-1.73(\mathrm{~m}, 1 \mathrm{H}), 1.72-1.67$ $(\mathrm{m}, 2 \mathrm{H}), 1.65-1.61(\mathrm{~m}, 2 \mathrm{H}), 1.50-1.42(\mathrm{~m}, 2 \mathrm{H}), 1.41-$ $1.33(\mathrm{~m}, 2 \mathrm{H}), 1.18$ (s, 3H), 1.03 (dd, $J=12.2,2.1 \mathrm{~Hz}, 1 \mathrm{H})$, $1.00-0.93(\mathrm{~m}, 1 \mathrm{H}), 0.91(\mathrm{~s}, 3 \mathrm{H}), 0.89(\mathrm{~s}, 3 \mathrm{H}), 0.85(\mathrm{~s}, 3 \mathrm{H})$. ${ }^{13} \mathrm{C}$ NMR $\left(101 \mathrm{MHz}, \mathrm{CDCl}_{3}\right) \delta 153.00,147.28,123.08$, $117.52,114.43,113.14,76.75,56.23,55.80,52.21,41.93$, $41.23,39.32,36.91,33.56,33.32,22.78,21.74,20.81$, $19.88,18.65,14.98$. Compound $6 \mathbf{a}$ was confirmed unambiguously by X-ray single crystal with the CCDC number of 1992589.

The etherified derivatives $(\mathbf{6 b} \sim \mathbf{6 g})$ were synthesized through similar manipulation.

2.2.2 General procedure for synthesis etherified derivatives 
$(6 \mathbf{h} \sim 6 \mathbf{k})$ of (+)-chromazonarol

To a $10 \mathrm{~mL}$ Schlenk tube containing a stirring bar was charged with (+)-chromazonarol (62 mg, $0.2 \mathrm{mmol}, 1.0$ equiv.), aryl bromide (if solid, $0.24 \mathrm{mmol}$ ), copper(I) iodide (3.8 mg, $0.02 \mathrm{mmol}, 10 \mathrm{~mol} \%$ ), picolinic acid (4.9 mg, 0.04 mmol, $20 \mathrm{~mol} \%)$ and $\mathrm{K}_{3} \mathrm{PO}_{4}(84.8 \mathrm{mg}, 0.4 \mathrm{mmol})$. The tube was evacuated and back-filled with $\mathrm{N}_{2}$ for 3 times. Then, aryl bromide (if liquid, $0.24 \mathrm{mmol}$ ) and $0.4 \mathrm{~mL}$ of DMSO were added. The reaction mixture was stirred vigorously for $24 \mathrm{~h}$ at $90{ }^{\circ} \mathrm{C}$. The reaction mixture was cooled to room temperature. Ethyl acetate $(5 \mathrm{~mL})$ and $\mathrm{H}_{2} \mathrm{O}(1 \mathrm{~mL})$ were added and the mixture was stirred. The organic layer was separated and the aqueous layer was extracted twice more with ethyl acetate $(10 \mathrm{~mL})$. The combined organic phase was washed with brine $(10 \mathrm{~mL})$, dried over anhydrous $\mathrm{Na}_{2} \mathrm{SO}_{4}$, and concentrated under vacuum. Purification by silica gel column chromatography on silica gel (200-300 mesh) with hexane/EtOAc $=5: 1(\mathrm{v} / \mathrm{v})$ as the eluent to give the desired compound.

2.2.3 General procedure for synthesis esterified derivatives (7c $\sim 7 \mathbf{k})$ of $(+)$-chromazonarol

To a stirred solution of (+)-chromazonarol $(81 \mathrm{mg}, 0.25$ mmol $)$ in anhydrous $\mathrm{CH}_{2} \mathrm{Cl}_{2}(10 \mathrm{~mL})$ was added acid $(0.25$ $\mathrm{mmol}$ ) followed by the addition of 1-Ethyl-3-(3dimethylaminopropyl) carbodiimide hydrochloride (EDCi$\mathrm{HCl})(62 \mathrm{mg}, 0.325 \mathrm{mmol})$ and dimethylaminopyridine (9 $\mathrm{mg}, 0.05 \mathrm{mmol})$ in an ice bath. The mixture was stirred and allowed to warm to ambient temperature until it was complete as monitored by TLC. The mixture was added a saturated aqueous solution of $\mathrm{NH}_{4} \mathrm{Cl}(10 \mathrm{~mL})$ and $\mathrm{CH}_{2} \mathrm{Cl}_{2}$ $(10 \mathrm{~mL})$, and the combined organic phases were washed with water $(3 \times 15 \mathrm{~mL})$ and brine $(15 \mathrm{~mL})$, then dried over anhydrous $\mathrm{Na}_{2} \mathrm{SO}_{4}$, filtered, and concentrated. The residue was purified by flash chromatography (200-300 mesh) with $\mathrm{PE} / \mathrm{EtOAc}=20: 1(\mathrm{v} / \mathrm{v})$ as eluent to give the desired esterified compound.

As shown in Figure 2, (+)-chromazonarol was reacted with different acyl chloride to obtain the esterified derivatives $\mathbf{7 a}$ and $\mathbf{7 b}$.

\subsubsection{Synthesis of compound $\mathbf{8}$}

To a stirred solution of (+)-chromazonarol ( $0.4 \mathrm{mmol}, 124.8$ $\mathrm{mg})$ in anhydrous $\mathrm{CH}_{2} \mathrm{Cl}_{2}(10 \mathrm{~mL})$ was added $\mathrm{Et}_{3} \mathrm{~N}(0.8$ $\mathrm{mmol}, 110 \mu \mathrm{L})$ followed by the addition of $\left(\mathrm{CF}_{3} \mathrm{SO}_{2}\right)_{2} \mathrm{O}(0.8$ $\mathrm{mmol}, 134 \mu \mathrm{L})$ in an ice bath. The reaction mixture was stirred at room temperature for $6 \mathrm{~h}$. The reaction mixture was diluted with brine $(10 \mathrm{~mL})$ and extracted with DCM $(2 \times 10 \mathrm{~mL})$. The combined organics were dried over $\mathrm{Na}_{2} \mathrm{SO}_{4}$, and concentrated in vacuo. The residue was purified by flash chromatography (200-300 mesh) with $\mathrm{PE} /$ EtOAc $=$ $10: 1(\mathrm{v} / \mathrm{v})$ as eluent to afford the product $\mathbf{8}$ (yellow oil) in $89 \%$ yield. ${ }^{1} \mathrm{H}$ NMR $\left(500 \mathrm{MHz}, \mathrm{CDCl}_{3}\right) \delta 6.98-6.92(\mathrm{~m}, 2 \mathrm{H})$, $6.75(\mathrm{~d}, J=8.6 \mathrm{~Hz}, 1 \mathrm{H}), 2.67-2.58(\mathrm{~m}, 2 \mathrm{H}), 2.07(\mathrm{dt}, J=$ $12.5,3.2 \mathrm{~Hz}, 1 \mathrm{H}), 1.83-1.71(\mathrm{~m}, 1 \mathrm{H}), 1.71-1.59(\mathrm{~m}, 4 \mathrm{H})$, $1.51-1.45(\mathrm{~m}, 1 \mathrm{H}), 1.44-1.34(\mathrm{~m}, 2 \mathrm{H}), 1.19(\mathrm{~s}, 3 \mathrm{H}), 1.15$ $(\mathrm{dd}, J=13.5,4.2 \mathrm{~Hz}, 1 \mathrm{H}), 1.02(\mathrm{dd}, J=12.3,2.3 \mathrm{~Hz}, 1 \mathrm{H})$, $0.96(\mathrm{td}, J=13.0,3.7 \mathrm{~Hz}, 1 \mathrm{H}), 0.91$ (s, 3H), 0.88 (s, 3H), $0.84(\mathrm{~s}, 3 \mathrm{H}) .{ }^{13} \mathrm{C}$ NMR $\left(126 \mathrm{MHz}, \mathrm{CDCl}_{3}\right) \delta 153.07,142.31$, 124.14, 122.34, 119.99, 118.25 (2C), 77.98, 56.18, 51.58, $41.86,41.04,39.27,36.94,33.53,33.32,22.61,21.69$, $20.95,19.81,18.59,15.03$

2.2.5 General procedure for synthesis biphenyl derivatives of $(+)$-chromazonarol

An oven-dried Schlenk tube was charged with $8(0.1 \mathrm{mmol}$, $45 \mathrm{mg})$, phenylboronic acid $(0.2 \mathrm{mmol}), \mathrm{Pd}(\mathrm{OAc})_{2}(0.004$ mmol, $0.89 \mathrm{mg}$ ), Xphos (0.004 mmol, $1.9 \mathrm{mg}$ ) and $\mathrm{K}_{3} \mathrm{PO}_{4}$ $(0.28 \mathrm{mmol}, 59 \mathrm{mg})$ was evacuated and refilled with $\mathrm{N}_{2}$ three times, followed by adding anhydrous Tetrahydrofuran $(1.0 \mathrm{~mL})$. The reaction mixture was stirred at $75^{\circ} \mathrm{C}$ for $8 \mathrm{~h}$. The reaction mixture was cooled to room temperature and diluted with water $(10 \mathrm{~mL})$, then extracted with EtOAc (2 $\times 10 \mathrm{~mL}$ ). The combined organic phases were washed with brine $(15 \mathrm{~mL})$, then dried over anhydrous $\mathrm{Na}_{2} \mathrm{SO}_{4}$, and concentrated in vacuo. The residue was purified by column chromatography (200-300 mesh) with PE/EtOAc $=10: 1$ $(\mathrm{v} / \mathrm{v})$ as eluent to afford the compound.

2.2.6 General procedure for synthesis carbamate derivatives of $(+)$-chromazonarol

To a stirred solution of (+)-chromazonarol (46.8 mg, 0.15 mmol) in anhydrous $\mathrm{CH}_{2} \mathrm{Cl}_{2}(5 \mathrm{~mL})$ were added triethylamine $\left(\mathrm{Et}_{3} \mathrm{~N}\right)(17375 \mu \mathrm{L}, 1.24 \mathrm{mmol}, 8.3 \mathrm{eq})$ and Isocyanate $(0.225 \mathrm{mmol})$ dropwise at $0^{\circ} \mathrm{C}$. Subsequently, the mixture was stirred and the system gradually risen to room temperature. The reaction progress was monitored by TLC until the reaction was completed $(\sim 5 \mathrm{~h})$. The solvent was removed under reduced pressure, and to the residue was added a saturated aqueous solution of $\mathrm{NH}_{4} \mathrm{Cl}(10 \mathrm{~mL})$ and $\mathrm{CH}_{2} \mathrm{Cl}_{2}(10$ $\mathrm{mL})$. The organic layer was separated, and the aqueous phase was extracted with $\mathrm{CH}_{2} \mathrm{Cl}_{2}(2 \times 10 \mathrm{~mL})$. The combined organic layers were washed with brine $(10 \mathrm{~mL})$, dried over $\mathrm{Na}_{2} \mathrm{SO}_{4}$, and concentrated. The residue was purified by flash chromatography (200-300 mesh) with PE/EtOAc = $10: 1(\mathrm{v} / \mathrm{v})$ as eluent to give the compound.

\subsubsection{Synthesis of compound 11a}

To a solution of (+)-chromazonarol $(39 \mathrm{mg}, 0.12 \mathrm{mmol}, 1.0$ equiv.) in DMF (4 mL) was added NCS (19.5 mg, 0.14 mmol, 1.2 equiv.) at $\mathrm{rt}$. Then the reaction mixture was stirred at $100{ }^{\circ} \mathrm{C}$ until the full conversion of (+)chromazonarol monitored by TLC (about $5 \mathrm{~h}$ ). Water was 
added to the reaction mixture and the reaction mixture was extracted with ethyl acetate $(3 \times 10 \mathrm{~mL})$. The organic layer was collected and washed brine, dried over anhydrous $\mathrm{Na}_{2} \mathrm{SO}_{4}$, filtered and concentrated under pressure to give crude products. The residue was purified by flash chromatography (200-300 mesh) with PE/EtOAc $=10: 1(\mathrm{v} / \mathrm{v})$ as eluent to give the compound 11a (54\%, colorless oil). ${ }^{1} \mathrm{H}$ NMR (500 MHz, $\left.\mathrm{CDCl}_{3}\right) \delta 6.79(\mathrm{~d}, J=8.7 \mathrm{~Hz}, 1 \mathrm{H}), 6.63(\mathrm{~d}$, $J=8.7 \mathrm{~Hz}, 1 \mathrm{H}), 2.70(\mathrm{dd}, J=17.2,5.4 \mathrm{~Hz}, 1 \mathrm{H}), 2.42(\mathrm{dd}, J$ $=17.2,13.1 \mathrm{~Hz}), 2.05(\mathrm{dt}, J=12.5,3.3 \mathrm{~Hz}, 1 \mathrm{H}), 1.82-1.71$ (m, 2H), $1.72-1.58(\mathrm{~m}, 3 \mathrm{H}), 1.55-1.43(\mathrm{~m}, 1 \mathrm{H}), 1.44-$ $1.37(\mathrm{~m}, 2 \mathrm{H}), 1.19(\mathrm{dd}, J=13.4,4.3 \mathrm{~Hz}, 1 \mathrm{H}), 1.14(\mathrm{~s}, 3 \mathrm{H})$, $1.03(\mathrm{dd}, J=12.5,2.3 \mathrm{~Hz}, 1 \mathrm{H}), 0.98-0.94(\mathrm{~m}, 1 \mathrm{H}), 0.91(\mathrm{~s}$, $6 \mathrm{H}), 0.85(\mathrm{~s}, 3 \mathrm{H}) .{ }^{13} \mathrm{C}$ NMR $\left(126 \mathrm{MHz}, \mathrm{CDCl}_{3}\right) \delta 147.52$, $144.89,121.06,119.88,116.32,114.06,76.61,56.25,51.82$, $41.92,40.92,39.30,36.97,33.56,33.34,21.73$ (2C), 20.58, $19.85,18.62,14.92$.

\subsection{Synthesis of (+)-8-epi-puupehedione $\mathbf{1 8}$}

To a solution of $17(68.4 \mathrm{mg}, 0.2 \mathrm{mmol})$ in 1,4-dioxane (4 $\mathrm{mL}$ ) was added DDQ (181.6 mg, $0.8 \mathrm{mmol})$ and $\mathrm{TsOH} \cdot \mathrm{H}_{2} \mathrm{O}$ (38 mg, $0.2 \mathrm{mmol}$ ) at room temperature. The mixture was warmed to $110{ }^{\circ} \mathrm{C}$ and stirred for $24 \mathrm{~h}$. After $24 \mathrm{~h}$, the solvent was removed in vacuo and the residue was purified by silica gel column chromatography on silica gel (200-300 m) with petroleum ether/EtOAc $(4: 1, \mathrm{v} / \mathrm{v})$ as the eluent gave the product (+)-8-epi-Puupehedione 18 (29 mg, $44 \%$, red solid). ${ }^{1} \mathrm{H}$ NMR $\left(500 \mathrm{MHz}, \mathrm{CDCl}_{3}\right) \delta 6.27(\mathrm{~s}, 1 \mathrm{H}), 6.13(\mathrm{~s}, 1 \mathrm{H})$, $5.93(\mathrm{~s}, 1 \mathrm{H}), 2.24-2.19(\mathrm{~m}, 1 \mathrm{H}), 1.93-1.62(\mathrm{~m}, 6 \mathrm{H}), 1.59$ (s, 3H), $1.56-1.52(\mathrm{~m}, 1 \mathrm{H}), 1.49-1.39(\mathrm{~m}, 1 \mathrm{H}), 1.20-$ $1.13(\mathrm{~m}, 4 \mathrm{H}(\mathrm{s}, 1.18)), 1.10(\mathrm{dd}, J=12.2,2.2 \mathrm{~Hz}, 1 \mathrm{H}), 0.93$ (s, 3H), 0.89 (s, 3H). ${ }^{13} \mathrm{C}$ NMR $\left(126 \mathrm{MHz}, \mathrm{CDCl}_{3}\right) \delta 181.19$, $179.66,166.40,164.36,137.87,122.29,114.47,108.11$, $83.16,53.13,41.27,41.17,40.39,37.74,34.21,33.30$, $30.82,22.06,21.81,19.31,18.71$. All spectral data matches that of previously reported.

\subsection{Synthesis of (+)-Pelorol Analogue 33}

To a solution of $32(21 \mathrm{mg}, 0.06 \mathrm{mmol})$ in anhydrous $\mathrm{CH}_{2} \mathrm{Cl}_{2}(4 \mathrm{~mL})$ was added $\mathrm{BBr}_{3}\left(0.27 \mathrm{~mL}, 1.0 \mathrm{M}\right.$ in $\mathrm{CH}_{2} \mathrm{Cl}_{2}$, $0.27 \mathrm{mmol}$ ). at ambient temperature. The reaction mixture was stirred until full conversion as monitored by TLC. A saturated $\mathrm{NaHCO}_{3}$ aqueous solution $(10 \mathrm{~mL})$ was added to quench the reaction. The separated aqueous phase was extracted with $\mathrm{CH}_{2} \mathrm{Cl}_{2}(3 \times 10 \mathrm{~mL})$. The combined organic phases were washed with $\mathrm{H}_{2} \mathrm{O}(10 \mathrm{~mL})$ and brine $(10 \mathrm{~mL})$, dried over anhydrous $\mathrm{Na}_{2} \mathrm{SO}_{4}$, filtered, and concentrated under reduced pressure to give a crude product. The resultant residue was purified by chromatography on silica gel (200-300 m) with petroleum ether/EtOAc $(3: 1, \mathrm{v} / \mathrm{v})$ as the eluent gave the 33 (18 mg, $95 \%$, white solid). ${ }^{1} \mathrm{H}$ NMR $\left(500 \mathrm{MHz}, \mathrm{CDCl}_{3}\right) \delta 6.31(\mathrm{~s}, 1 \mathrm{H}), 6.08(\mathrm{~s}, 1 \mathrm{H}), 2.62-2.55$ (m, 1H), 2.48 (dd, $J=14.6,6.2 \mathrm{~Hz}, 1 \mathrm{H}), 2.33-2.28(\mathrm{~m}$,
$1 \mathrm{H}), 1.85-1.66(\mathrm{~m}, 4 \mathrm{H}), 1.65-1.58(\mathrm{~m}, 1 \mathrm{H}), 1.54-1.48$ (m, 1H), $1.45-1.38(\mathrm{~m}, 2 \mathrm{H}), 1.18(\mathrm{td}, J=13.6,13.1,4.4$ $\mathrm{Hz}, 1 \mathrm{H}), 1.12$ (s, 3H), $1.04-0.97$ (m, 5H), 0.87 (s, 6H). ${ }^{13} \mathrm{C}$ NMR $\left(126 \mathrm{MHz}, \mathrm{CDCl}_{3}\right) \delta 155.02,151.57,146.25,131.38$, $105.35,101.24,64.62,57.41,45.90,42.68,40.24,38.71$, $37.05,33.54,33.28,29.40,21.23,21.01,19.69,18.44$, 16.25. All spectral data matches that of previously reported.

\subsection{Synthesis of $(+)$-Albaconol}

\subsubsection{Synthesis of compound $\mathbf{4 0}$}

To a solution of 3,5-dihydroxytoluene $(620 \mathrm{mg}, 5.0$ mmol) in methanol $(25 \mathrm{~mL})$ at $0{ }^{\circ} \mathrm{C}$ was added NBS $(2.62 \mathrm{~g}$, $15 \mathrm{mmol}, 3.0$ equiv.). The reaction was stirred at $0{ }^{\circ} \mathrm{C}$ for 2 h. A solution of $\mathrm{Na}_{2} \mathrm{SO}_{3}(1.25 \mathrm{~g}, 10 \mathrm{mmol}, 2.0$ equiv.) and $\mathrm{NaOH}(0.4 \mathrm{~g}, 10 \mathrm{mmol}, 2.0$ equiv.) in water $(25 \mathrm{~mL})$ was added, and it was reacted for $1 \mathrm{~h}$. Conc. $\mathrm{HCl}$ was added to tune the $\mathrm{pH}$ to 1.0 . The crude mixture was extracted with EtOAc $(15 \mathrm{~mL} \times 2)$. The combined organic layer was dried over $\mathrm{Na}_{2} \mathrm{SO}_{4}$, filtered, and concentrated. The residue was purified by column chromatography on silica gel (200-300 $\mathrm{m})$ with petroleum ether/EtOAc $(\mathrm{v} / \mathrm{v}, 3 / 1)$ as the eluent gave product 2-bromo-phen-1,3-diol (white solid, $712 \mathrm{mg}, 71 \%$ ). To a stirred solution of the 2-bromo-phen-1,3-diol (203 mg, 1.00 mmol, 1.0 equiv.) and $\mathrm{K}_{2} \mathrm{CO}_{3}(245 \mathrm{mg}, 2.50 \mathrm{mmol}, 2.5$ equiv.) in DMF $(5.0 \mathrm{~mL})$ was added benzyl bromide (296 $\mu \mathrm{L}, 2.5 \mathrm{mmol}, 2.5$ equiv.) at $\mathrm{rt}$. The resultant mixture was stirred at $90^{\circ} \mathrm{C}$ over night before it was quenched with saturated aq. $\mathrm{NH}_{4} \mathrm{Cl}(10.0 \mathrm{~mL})$ and extracted with EtOAc (3 $\times 10 \mathrm{~mL}$ ). The combined organic phases were washed with water $(10 \mathrm{~mL})$ and brine $(10 \mathrm{~mL})$, dried over anhydrous $\mathrm{Na}_{2} \mathrm{SO}_{4}$, filtered, and concentrated under vacuum. The residue was purified by column chromatography on silica gel (200-300 m) with petroleum ether/EtOAc (v/v, 5/1) as the eluent gave product (40, white solid, $200 \mathrm{mg}, 52 \%) .{ }^{1} \mathrm{H}$ $\operatorname{NMR}\left(500 \mathrm{MHz}, \mathrm{CDCl}_{3}\right) \delta 7.50(\mathrm{~d}, J=7.3 \mathrm{~Hz}, 4 \mathrm{H}), 7.42-$ 7.37 (m, 4H), $7.35-7.30$ (m, 2H), $6.46(\mathrm{~s}, 2 \mathrm{H}), 5.15$ (s, 4H), $2.29(\mathrm{~s}, 3 \mathrm{H})$. All spectral data matches that of previously reported.

\subsubsection{Synthesis of (+)-Albaconol 41}

To a schlenck flask equipped with a stir bar, $\operatorname{Pd}_{2}(\mathrm{dba})_{3}$ (4.6 mg, $0.005 \mathrm{mmol}, 0.02$ equiv.), $\mathrm{NaOtBu}$ (0.062 g, 0.63 mmol, 2.5 equiv.), RuPhos ( $4.7 \mathrm{mg}, 0.01 \mathrm{mmol}, 0.04$ equiv.), $40(0.107 \mathrm{~g}, 0.28 \mathrm{mmol}, 1.1$ equiv. $)$ and $1(0.1 \mathrm{~g}, 0.255$ mmol, 1.0 equiv.) were added sequentially. The flask was evacuated and filled with $\mathrm{N}_{2}$ (three cycles), tert-butanol (1.0 $\mathrm{mL}), \mathrm{H}_{2} \mathrm{O}(0.1 \mathrm{~mL})$ were added in turn by syringe under an $\mathrm{N}_{2}$ atmosphere. The resulting reaction mixture was stirred vigorously at $100^{\circ} \mathrm{C}$. After $18 \mathrm{~h}$, the reaction was completed as detected by TLC. The reaction mixture was then diluted with EtOAc $(20 \mathrm{~mL})$, the reaction mixture was washed by saturated brine $(10 \mathrm{~mL} \times 2)$. The organic layer was dried over anhydrous $\mathrm{Na}_{2} \mathrm{SO}_{4}$, and concentrated under vacuum. 
The residue was purified by column chromatography on silica gel (200-300 m) with petroleum ether/EtOAc (v/v, $10 / 1 \rightarrow 8 / 1)$ as the eluent gave the product 19a (70 mg, $52 \%$, colorless oil).

To a stirred solution of the 19a $(64 \mathrm{mg}, 0.12 \mathrm{mmol}, 1.0$ equiv.) and ammonium formate (277 $\mathrm{mg}, 4.38 \mathrm{mmol}, 36.0$ equiv.) in $\mathrm{MeOH}(5.0 \mathrm{~mL})$ was added $\mathrm{Pd} / \mathrm{C}(5 \%, 277 \mathrm{mg}$, $2.48 \mathrm{mmol}, 20.0$ equiv.) at $\mathrm{rt}$. The resultant mixture was stirred and at reflux temperature. After the complete disappearance of the 19a (monitored by TLC), the reaction mixture was cooled to rt and filtered. The filtrate was washed twice with $\mathrm{MeOH}$. Evaporation of the solvent under reduced pressure and purified by column chromatography on silica gel (200-300 m) with petroleum ether/EtOAc $(5: 1, \mathrm{v} / \mathrm{v})$ as the eluent gave the product $(+)$-Albaconol $41(16 \mathrm{mg}$, $38 \%$, white solid). ${ }^{1} \mathrm{H}$ NMR (500 MHz, Acetone-d $\left.{ }_{6}\right) \delta 8.61$ (s, $2 \mathrm{H}), 6.10$ (s, $2 \mathrm{H}), 5.08$ (s, $1 \mathrm{H}), 3.01$ (dd, $J=15.3,7.5$ $\mathrm{Hz}, 1 \mathrm{H}), 2.44(\mathrm{~d}, J=15.3 \mathrm{~Hz}, 1 \mathrm{H}), 2.17-2.12(\mathrm{~m}, 1 \mathrm{H})$, $2.09(\mathrm{~s}, 3 \mathrm{H}), 1.94-1.89(\mathrm{~m}, 1 \mathrm{H}), 1.68-1.59(\mathrm{~m}, 3 \mathrm{H}), 1.59$ $-1.49(\mathrm{~m}, 1 \mathrm{H}), 1.39-1.30(\mathrm{~m}, 1 \mathrm{H}), 1.30-1.26(\mathrm{~m}, 4 \mathrm{H}(\mathrm{s}$, $1.29)), 1.23-1.17(\mathrm{~m}, 1 \mathrm{H}), 1.06(\mathrm{td}, J=13.4,4.1 \mathrm{~Hz}, 1 \mathrm{H})$, 0.97 (s, 3H), 0.92 (dd, $J=12.2,2.1 \mathrm{~Hz}, 1 \mathrm{H}), 0.85(\mathrm{~s}, 3 \mathrm{H})$, $0.81(\mathrm{~s}, 3 \mathrm{H}), 0.56(\mathrm{td}, J=13.3,3.6 \mathrm{~Hz}, 1 \mathrm{H}) .{ }^{13} \mathrm{C} \mathrm{NMR}(126$ $\mathrm{MHz}$, Acetone-d $\left.{ }_{6}\right) \delta 156.59(2 \mathrm{C}), 136.64,114.12,108.59$ (2C), 75.57, 61.45, 57.07, 44.64, 42.65, 39.97, 38.52, 33.82, $33.75,24.36,21.88,21.20,21.05,18.97,18.74,15.45$. All spectral data matches that of the isolated natural product.

More experimental details and characterizations are available in the Supporting Information online.

\section{Results and discussion}

The $\mathrm{C}(\mathrm{sp} 3)$ enrichment characteristic of natural products always results in a higher probability of identifying hits. (+)-Chromazonarol has attracted increasing attention from both synthetic chemists and medicinal scientists as its unique structure and the identified various activities, while there was no report disclosed on the versatile derivatization and SAR of this natural product. More insights into the $(+)-$ chromazonarol relevant (pseudo-)natural products may show profound effect in the discovery of new chemical entities of pharmaceutical importance.

\subsection{Scalable synthesis of (+)-yahazunol and (+)- chromazonarol}

The interest in chromazonarol derivatives was sparked by the previous identification of its antifungal potential [22], while the diversity and semisynthetic modification was much limited. The practical and scalable process of generating $(+)$-chromazonarol was speculated as an onerous bottleneck en route to a diverse molecular library. Invigorated by our previous $\mathrm{C}(\mathrm{sp} 3)-\mathrm{C}(\mathrm{sp} 2)$ cross-coupling for efficient linking the drimane segment and aromatic parts, practical preparation of chromazonarol related meroterpenoids was conceived to initiate the investigation. Gratifyingly, the established tactic demonstrated feasibility with the genuinely complex natural products. The efficient synthesis of both $(+)$-yahazunol and $(+)$-chromazonarol was accomplished from the low-cost raw materials (-)-sclareol and 2bromobenzene-1,4-diol by merging decarboxylative borylation and Suzuki coupling (Scheme 1).

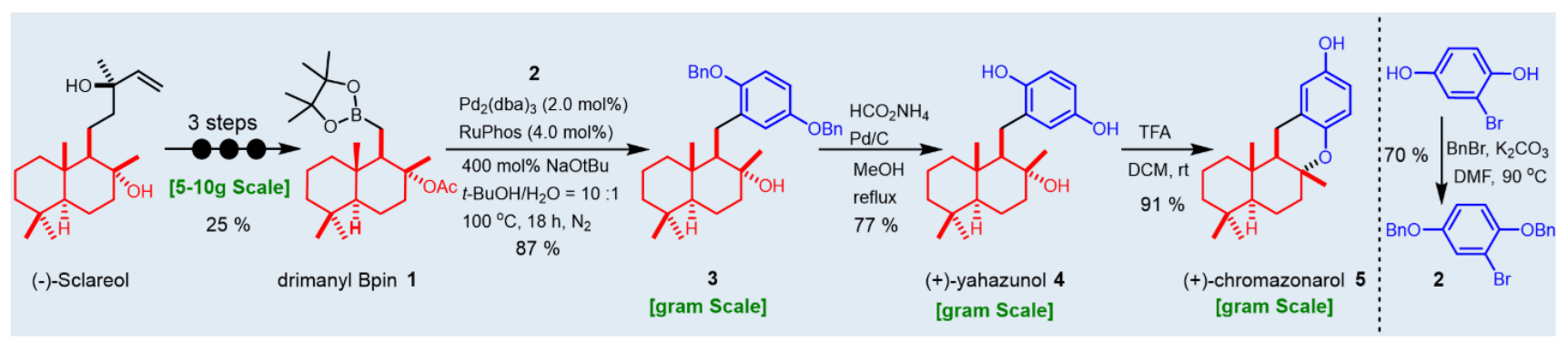

Scheme 1 Efficient synthesis of (+)-yahazunol and (+)-chromazonarol.

The bench stable and easily accessible drimanyl BPin $\mathbf{1}$ can be prepared in multigrams from inexpensive natural diterpene sclareol through $\mathrm{RuCl}_{3}$ catalyzed oxidation followed by the condensation with $N$-hydroxyphthalimide and $\mathrm{Cu}$-catalyzed borylation (see supporting information for a detailed procedure). The other part in this coupling paradigm for $(+)$-yahazunol, can be prepared easily from $O$ benzylated masked commercial phenols. The free phenol groups of commercially available 2-bromobenzene-1,4-diol was protected efficiently by benzyl bromide under basic conditions to give intermediate $\mathbf{2}$ in good yield. The follow- ing Pd catalyzed Suzuki coupling of drimanyl BPin 1 and arylbromide 2 went smoothly, and furnished (+)-yahazunol after reductive deprotection of benzyl group assisted by $\mathrm{Pd} / \mathrm{C}-\mathrm{HCOONH}_{4}$ system. Treatment of $(+)$-yahazunol with TFA in DCM furnished the $(+)$-chromazonarol in good yield. All the manipulations in this tactic (Scheme 1) were carried out in gram to decagram scale, providing a significant opportunity to scale up to sufficient quantities of (+)chromazonarol, which could enable structural modification to be explored along with biological activity. 


\subsection{Antifungal activity oriented complication of (+)- chromazonarol}

3.2.1 Synthesis of chromazonarol derivatives and (+)-8-epipuupehedione.

Considering the antifungal potentials and synthetic tractability, the natural product $(+)$-chromazonarol was selected as a lead for further modification to expand the chemical space aiming at improving biological potentials. The scaled reaction conditions shown in Scheme 1 identified the practical route in pursuit of ample quantities of $(+)$-chromazonarol. Functional group directed simple but important transformations including etherification and esterification were im- plemented firstly based on the phenolic hydroxyl group of (+)-chromazonarol (Figure 2A).

The aliphatic ethers $(\mathbf{6 a - 6 g})$ were prepared by treating $(+)$-chromazonarol with halogenated hydrocarbons through nucleophilic substitution prompted by sodium hydride in acetone, and the methyl ether $\mathbf{6 a}$ was confirmed unambiguously by X-ray single crystal with the CCDC number of 1992589. The aromatic congeners (6h-6k) were synthesized by copper-picolinic acid catalyzed Ullmann-type coupling in moderate to good yields. Esterified derivatives (7a-7k) were provided efficiently by either employing EDCI mediated steglich-type condensation or direct acylation with readily available acyl chloride in presence of a basic condition.

A. Synthesis of esterified and etherified derivatives of chromazonarol 5

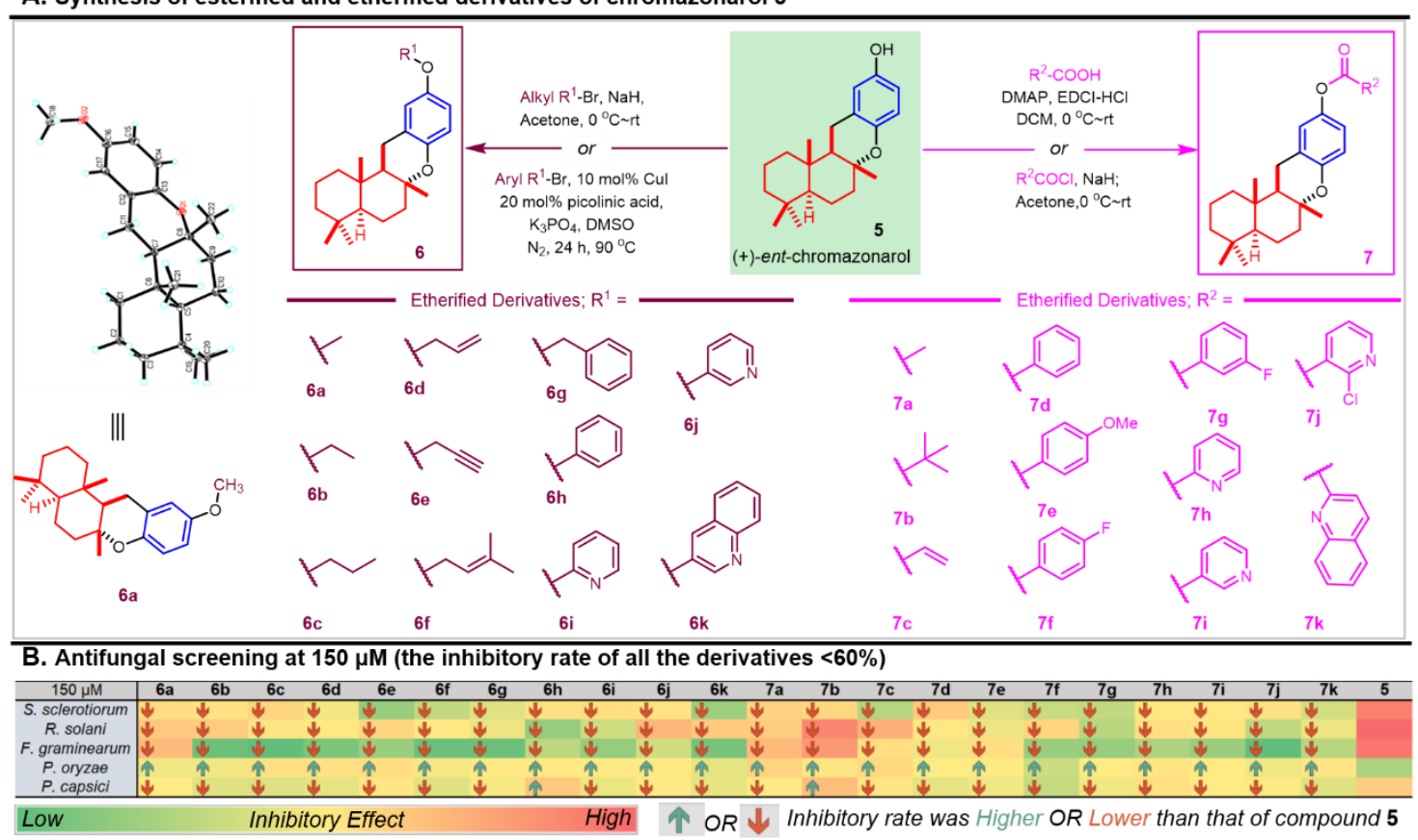

Figure 2 Synthesis and antifungal screening of ethers and esters of (+)-chromazonarol.

As shown in Figure 3A, our attention was next turned to decorate the medicinally important biphenyl segments or equivalents on the drimane scaffold. (+)-Chromazonarol was first transformed to the triflate intermediate $\mathbf{8}$, and then underwent palladium catalyzed Suzuki coupling with different arylboronic acids (9a-9c) or heteroarylboronic acids $(9 \mathbf{d}-9 \mathrm{~g})$. Noteworthily, introduction of different aromatic scaffolds requires a bespoke system and special attention should be paid to this transformation. Arylation of the chromazonarol triflate 8 went smoothly with less than 5 mol\% palladium catalyst, while the synthesis of hetero-variants 9e-9h need more rigorous conditions including a high catalyst loading and an elevation of temperature. Condensation of chromazonarol with the isocyanates gave a facile access to the carbamates 10a and 10b. Late-stage chlorination with chlorosuccinimide (NCS) provided chloro-chromazonarol 11a in good yield. 


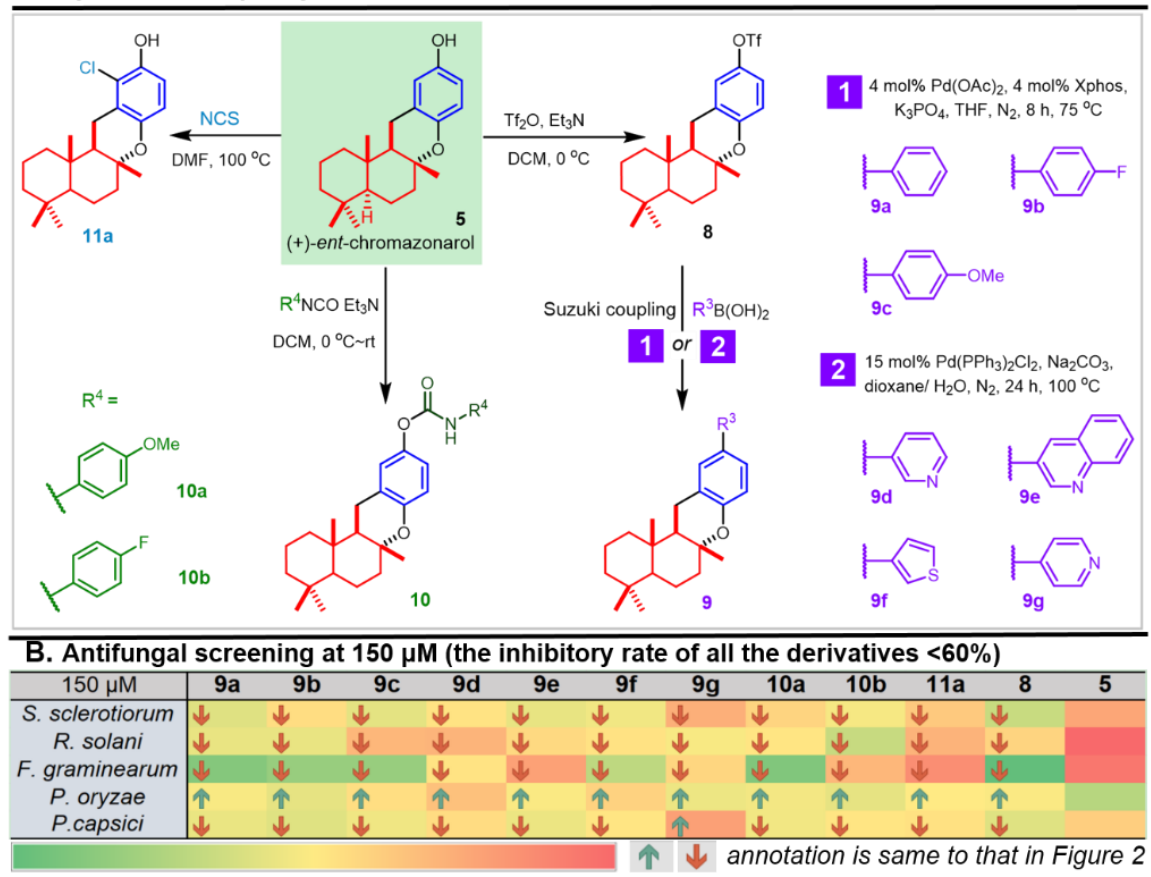

Figure 3 Synthesis and antifungal screening of biphenyl, carbamates and chloro derivatives of (+)-chromazonarol.

Based on the synthetic progress in (+)-chromazonarol, $(+)-8$-epi-puupehedione attracted our attention due to its reported enhanced bioactive potential than its natural congener puupehedione [27]. Meanwhile, the target molecule can be deemed as a structure-complicated analogue of (+)chromazonarol, and the intermediates $\mathbf{1 3}$ and $\mathbf{1 6}$ thereof can be added to the arsenal of yahazunol mimics (Scheme 2). 3,4-Dimethoxyphenol was selected as the starting aromatic segment, which was transformed conveniently to the coupling precursor $\mathbf{1 2}$ in two steps (vide supra). The Suzuki coupling with drimanyl Bpin 1, deprotection of benzyl group and Lewis acid catalyzed cyclization went smoothly to deliver chromazonarol mimic 14. Attempt in the demethylation of $\mathbf{1 4}$ with $\mathrm{BBr}_{3}$ in DCM didn't produce the desired hydroxylated chromazonarol. Alternatively, sesamol was employed instead of 3,4-dimethoxyphenol in the above transformation for the synthesis of chromazonarol mimic 17. Gratifyingly, the deprotection and oxidation was realized in one pot in presence of the mixture of $\mathrm{TsOH}-\mathrm{H}_{2} \mathrm{O}$ and DDQ, producing (+)-8-epi-puupehedione $\mathbf{1 8}$ in appreciable amount for bioactivity test. Compared with the previous synthetic tactics, either via the classic addition of aryllithium to carbonyl group [27-29], electrocyclization [30], biomimetic cyclization [31], Diels-Alder cycloaddition [24] or Friedel-Crafts alkylation [32] as a key step, or the modular synthesis by palladium-catalyzed tandem carbene migratory insertion [23] or "borono-sclareolide" coupling, this approach is an alternative but improved route to $(+)-8$-epipuupehedione, in terms of step-economy, stereo-fidelity, availability of starting materials or synthetic tractability (Scheme 2).

\subsubsection{Preliminary antifungal evaluation.}

Inspired by our previous discovery of (+)-chromazonarol as a novel natural antifungal lead, exploration of the antifungal potentials of its derivatives were commenced subsequently at the concentration of $150 \mu \mathrm{M}$ to probe the necessity for the direct decoration of this reference compound. As can be seen in Figure 2B and Figure 3B, the synthesized ethers $(\mathbf{6 a}-6 \mathbf{k})$, esters $(\mathbf{7 a - 7} \mathbf{k})$, arylated derivatives $(9 \mathbf{a}-\mathbf{9 g})$, carbamates (10a and 10b) and chlorinated mimic (11a) attenuated the inhibitory effect against the selected agriculturally important plant pathogens, including S. sclerotiorum, R. solani, and $F$. graminearum. The crucial role of the aromatic hydroxyl group may be attributed to the potential interaction with the amino acid residues of the protein targets via the hydrogen bonds. It is noteworthy that heteroaryl or biphenyl mimics of drimane hydroquinols have not been reported, suggesting that these fragments may be biosynthetically unrelated. The synthesized biaryl mimics may be beneficial for novel bioactivity, since they may be encoded by different enzymes. Interestingly, the artificial biaryl mimics (9a$9 g$ ) demonstrated an enhanced inhibitory effect against $P$. oryzae which was insensitive to (+)-chromazonarol. The small and electron-withdrawing aromatic with $\mathrm{H}$-bond acceptor characteristic was speculated to contribute to this effect (9d), and introducing ring-expanded mimic (9e) or thiphene (9f) didn't identify more promising leads albeit the antifungal effect against $P$. capsici was promoted. (+)-8-epiPuupehedione 18 was also subjected to this biotest, while it didn't elevate the antifungal effect in the phenotypic screening, either did its alkoxylated analogues 14 and 17. Overall, 
the phenolic hydroxyl group may be one inviolable requirement for antifungal effect, and direct derivatization for structural complication is not recommended in the view of either synthetic economy and feasibility or the enhancement in antifungal activities.

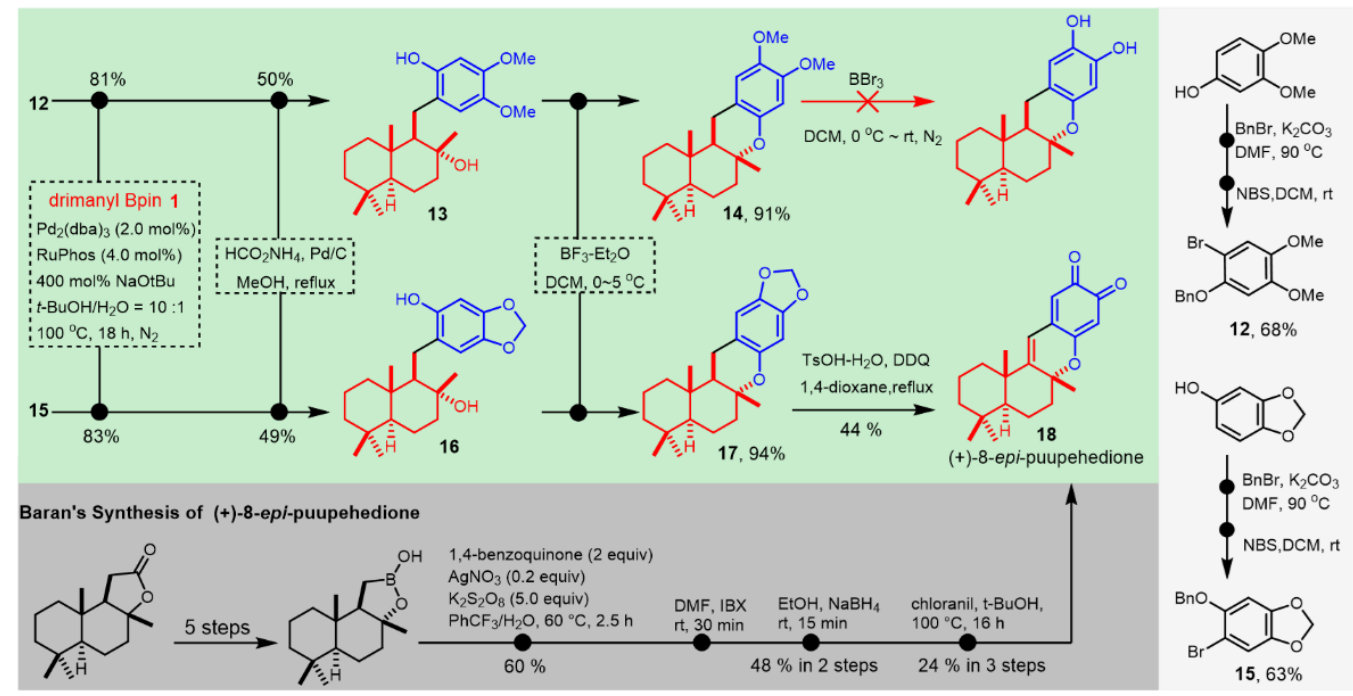

Scheme 2 Synthesis of (+)-8-epi-puupehedione and analogues of (+)-chromazonarol.

\subsection{Antifungal activity oriented simplication of (+)- chromazonarol}

3.3.1 Diverted synthesis of yahazunol isomers, chromazonarol isomers and relevant natural products.

The complexity without biological improvement in the optimization of chromazonarol stimulated our investigation to work backwards to (+)-yahazunol in pursuit of new simplified analogues to address biological issues. To assess the extent to which the position of hydroxyl group-dependent antifungal activity could be varied, a library of yahazunol isomers were prepared (Scheme 3). These simplified variants can be accessed easily and divergently by variation of the aromatic fragments in the Suzuki coupling with the advanced intermediate drimanyl BPin 1. Interestingly, a constellation of unprecedented isomers $(\mathbf{2 4}, \mathbf{2 5}, \mathbf{2 6}, 27$ and 28) of $(+)$-yahazunol were successfully prepared through this programmable manipulation (Scheme 3 ). The sterically hindered reactants may attenuate the efficacy in both the coupling and deprotection steps. It is noteworthy that compound 28 from this synthetic philosophy was the reported intermediate en route to (+)-8-epi-puupehedione [33].

As the description in Scheme 3, treatment of these isomeric yahazunols with TFA will led to the isomers of $(+)$ chromazonarol in good to excellent yields (80\%-97\%), in which compound 29 can be elected for the synthesis of hongoquercin A [34]. Alternatively, (+)-yahazunol isomer 27 from 1-bromo-3,5-dimethoxybenzene was chosen for the construction of 6-6-5-6 ring fused skeleton 32 featured in pelorol. The structure was confirmed by single-crystal Xray diffraction (CCDC NO. 2096788) and the subsequent demethylation with $\mathrm{BBr}_{3}$ could produce the previously reported promising SHIP2 inhibitor 33, which was more straightforward and efficient than the original one developed by Andersen. [35]

This also provided an alternative approach to $(+)$ dictyvaric acid 34 (Scheme 4), the natural product isolated from the brown alga Dictyopteris divaricata Okam [26, 36]. Meanwhile, the formally reductive analogue 35 to (+)dictyvaric acid was intentionally synthesized to study the SAR of yahazunol (vide infra).

Our work opened up a new opportunity to achieve other natural drimane hydroquinols. The first synthesis of the natural products (+)-neoalbaconol 37 and (+)-albaconol 41 was accomplished (Scheme 5), which were isolated and verified as promising antitumor and anti-inflammatory agents [37-42]. This will lay a good foundation for checking whether magic methyl effect exists in the antifungal screening compared with $\mathbf{2 4}$ and $\mathbf{2 5}$, respectively. Gratifyingly, drimanyl-(+)-neoalbaconol (39, or bidrimanyl 5methylresorcinol) was also synthesized in detectable yield based on the incipient dibromination of 5-methylresorcinol in $\mathrm{MeOH}$ media. This kind of condensed dimeric counterpart comprised of two sterically hindered drimane segments bridging by an aromatic unit via $\mathrm{C}(\mathrm{sp} 3)-\mathrm{C}(\mathrm{sp} 2)$ bond are far less prevalent in natural products. 


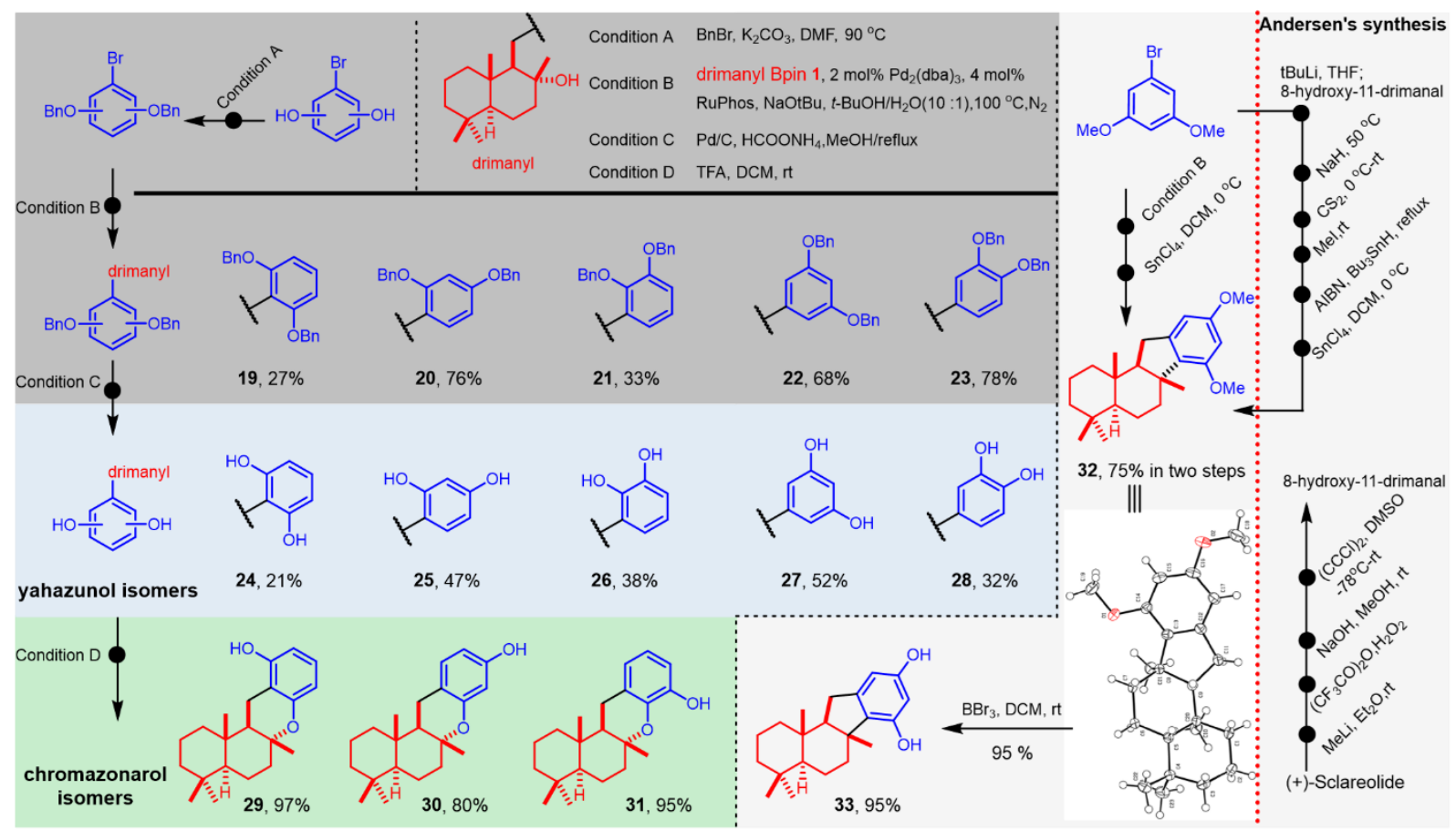

Scheme 3 Synthesis of isomers and analogues of $(+)$-yahazunol.

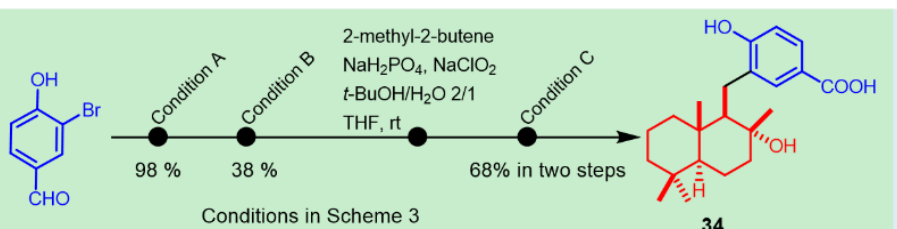

(+)-dictyvaric acid

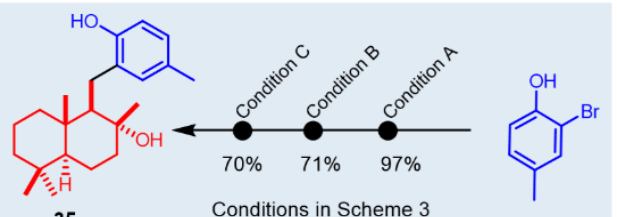

35

Conditions in Scheme 3 (+)-dictyvaric acid mimic

Scheme 4 Synthesis of (+)-dictyvaric acid and its mimic.
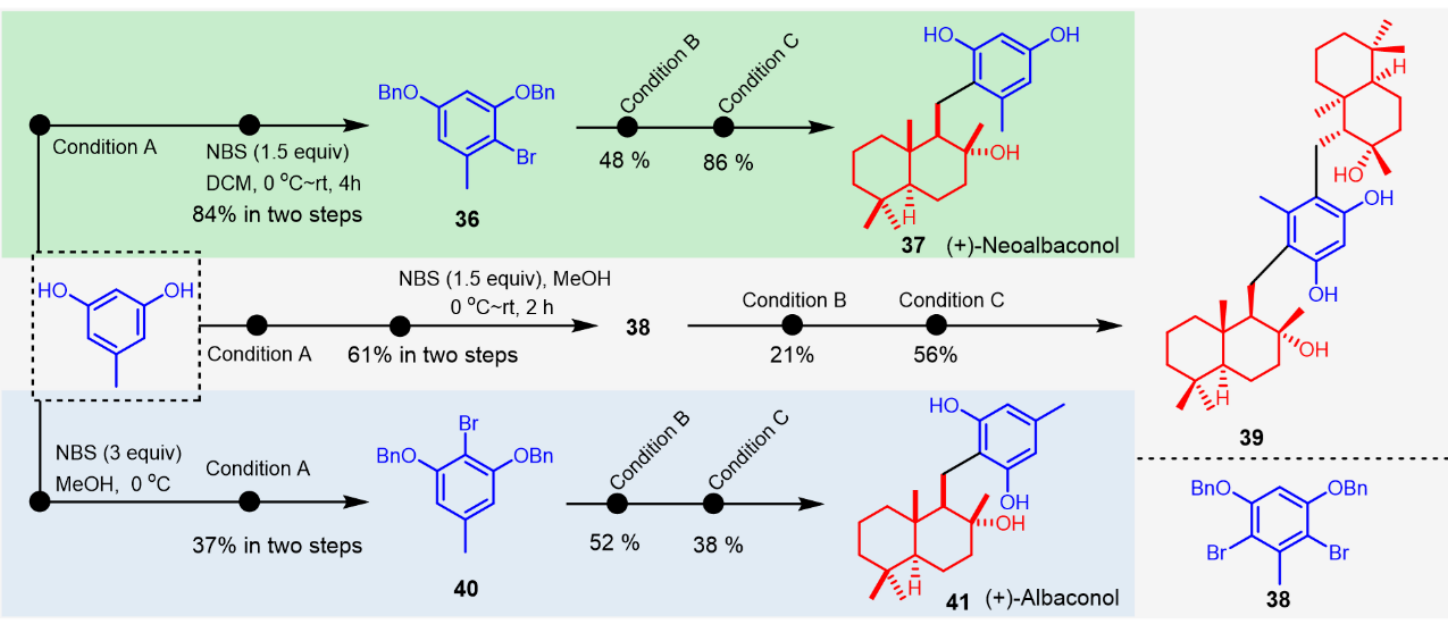

Scheme 5 Synthesis of (+)-neoalbaconol, (+)-albaconol and their mimics

\subsubsection{Preliminary antifungal evaluation.}

The established Suzuki coupling sets a powerful platform for efficient synthesis of yahazunol related meroterpenoids. Yahazunol isomers 24-28 were prepared as pseudo-natural products for antifungal screening. As can be seen in Figure 4 , the tiny ortho-migration of phenolic hydroxyl group from
C-18 position of yahazunol to either C-17 position or C-19 position, dramatically increased the antifungal potency exemplified by the synthesized pseudo natural products $\mathbf{2 4}$ and 25 possessing the inhibitory rate of $>80 \%$ against both $S$. sclerotiorum and $R$. solani. Resetting this hydroxyl group 
from $\mathrm{C}-18$ position to $\mathrm{C}-20$ position was tolerant as compound $26 \mathrm{kept}$ similar activity comparative to that of yahazunol. Curiously, shifting the C-21 hydroxyl group to C-20 position led to a sharp erosion of the antifungal potency against all the test fungi (27 vs 4). Interestingly, formally synchronous rearrangement of the hydroxyl groups of yahazunol for the acquirement of the new isomer 28, expanded the antifungal spectra than that of the mother natural product, as the inhibitory effect against $P$. oryzae and $P$. capsici was improved significantly.

Encouraged by these promising findings, the previously conformation-constrained optimization of (+)-yahazunol to $(+)$-chromazonarol with enhanced antifungal potential propelled us to investigate the chromanones 29,30 and $\mathbf{3 1}$ versus the corresponding precursors $\mathbf{2 4}, \mathbf{2 5}$ and $\mathbf{2 6}$. This optimization didn't enhance the effect against $S$. sclerotiorum, $R$. solani and F. graminearum compared with their corresponding flexible precursors $\mathbf{2 4}, \mathbf{2 5}$ and $\mathbf{2 6}$. The conformation restricted optimization to the 6-6-5-6 ring fused mimic of pelorol is necessary for enhancing the antifungal activity ( 33 vs 27). Worthy of note is that this is the first exploration of the antifungal potential of pelorol related analogue to our knowledge.

$(+)$-Dictyvaric acid was isolated more than 15 years ago from the brown alga Dictyopteris divaricata Okam, [36] while no specific bioactivities were disclosed. As a natural mimic of yahazunol via formally replacing the $\mathrm{C}-18$ hydroxyl group by a more polar carboxyl group, $(+)$-dictyvaric acid 34 could effectively inhibit both $S$. sclerotiorum and $R$. solani. The favor for the polar substituent was proofed by contradictory introduction of its mimic 35, which didn't show obvious inhibitory effect against all the fungi at 150 $\mu \mathrm{M}$.

Pinpoint decoration on the aromatic segment of yahazunol model continued with the first synthesis and antifungal test of (+)-neoalbaconol 37 and (+)-albaconol 41. To our delight, these two natural products showcased good inhibitory effect against $S$. sclerotiorum and (+)-neoalbaconol $\mathbf{3 7}$ demonstrated more promising tendency to inhibit $R$. solani. Interestingly, the magic methyl effect was observed as (+)neoalbaconol 37 gave more satisfying inhibitory effect against $P$ oryzae compared with that of the isomeric yahazunol 25.

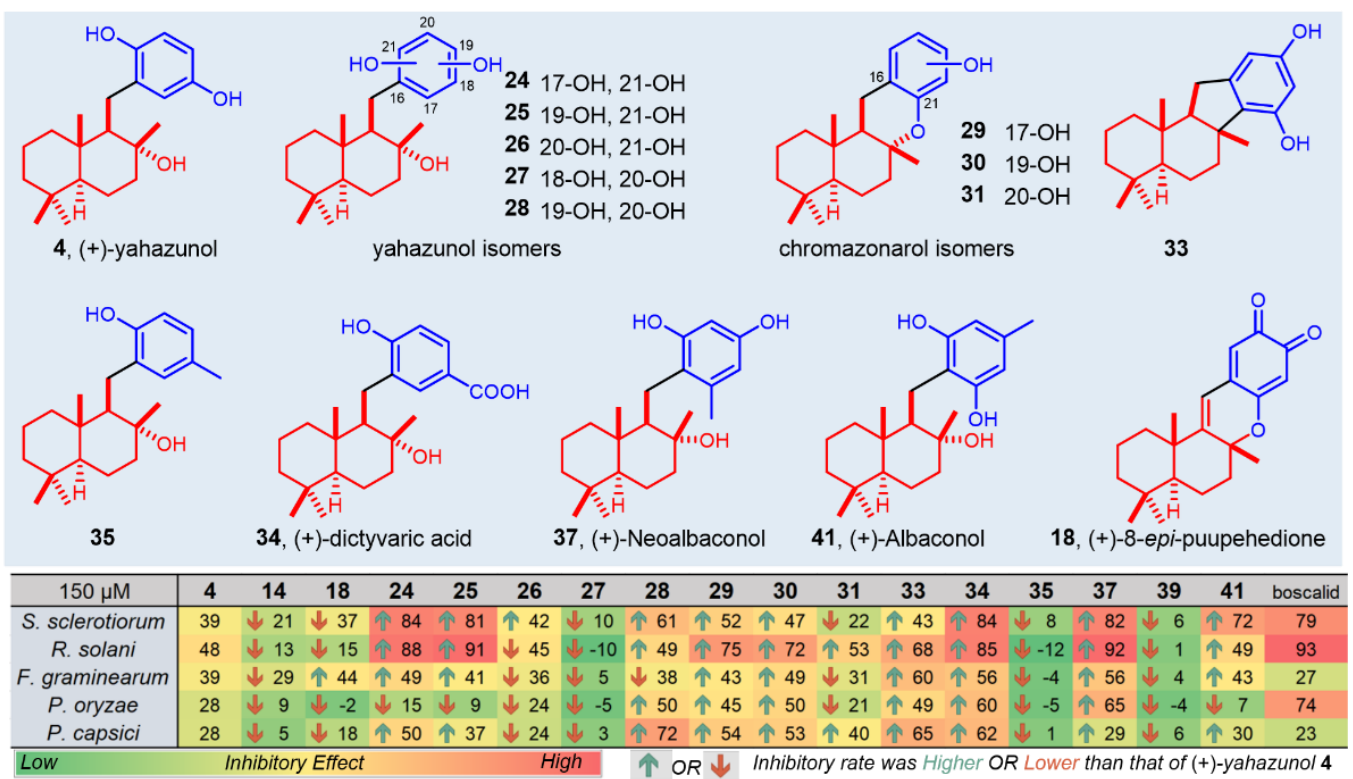

Figure 4 Antifungal screening of (+)-yahazunol relevant natural products, isomers and analogues.

\subsection{Yahazunol isomers and relevant natural products as novel pharmaceutical leads.}

The aforementioned modular access to the natural drimane hydroquinones, isomers, or analogues provided unprecedented chemical space for phenotypic screening, which facilitated the discovery of new leads or probes that may be different from natural products. In general, antifungal phenotypic screening was accomplished for all the synthesized natural products, unpresented isomers and derivatives at 150 $\mu \mathrm{M}$, yet low activity with the inhibitory rate of $<60 \%$ ex- cluded these natural products or mimics from further biological analysis. An overview of antifungal optimization guided structure and activity relationship was summarized in Figure 5.

Further antifungal test was carried out against selected fungi for promising natural products $(+)$-dictyvaric acid $\mathbf{3 4}$, $(+)$-neoalbaconol 37 and (+)-albaconol $\mathbf{4 1}$ together with the non-natural isomers $\mathbf{2 4}$ and $\mathbf{2 5}$ of (+)-yahazunol. Meanwhile, the antitumor activities of these compounds were also investigated to detect whether similar effect of specific structures on biological outcome occurred. 


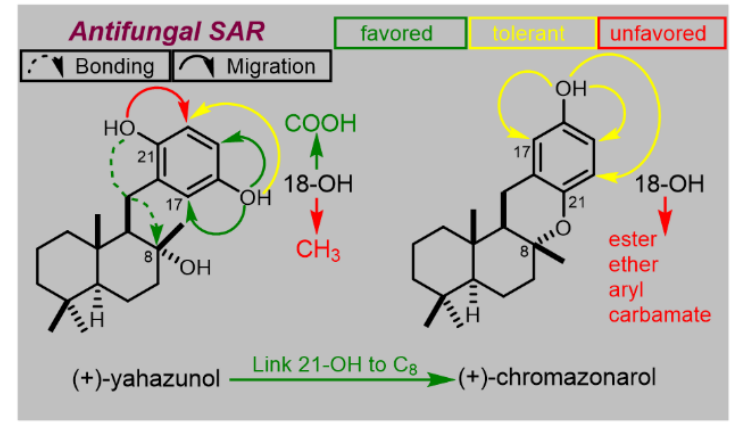

Figure 5 Antifungal SAR of (+)-yahazunol, (+)-chromazonarol and mimics.

The yahazunol isomers represented structures that were outside of the originally isolated natural counterparts, grounded in either rational design or bioactivity-guided scaffold diversification. As shown in Figure 4 and Figure 5, the tiny ortho-migration of phenolic hydroxyl group from $\mathrm{C}-18$ position to either $\mathrm{C}-17$ position or $\mathrm{C}-19$ position, showed more than 3-fold enhancement in antifungal activity with S. sclerotiorum and R. solani. Among this, the (+)yahazunol isomer 25, with the $\mathrm{EC}_{50}$ value lower to 15.19 $\mu \mathrm{M}$ against $S$. sclerotiorum, demonstrated $>10$-fold inhibitory improvement than the natural yahazunol. Without specific bioactivities disclosed ever since its isolation [36], (+)dictyvaric acid $\mathbf{3 4}$ was demonstrated as a fruitful modification for inhibiting both $S$. sclerotiorum and $R$. solani with
$\mathrm{EC}_{50}$ values of $22.16 \mu \mathrm{M}$ and $22.54 \mu \mathrm{M}$, respectively. Though further introduction of methyl group to (+)yahazunol isomers $\mathbf{2 4}$ and $\mathbf{2 5}$ didn't improve the antifungal effect obviously, the magic methyl effect was observed for the resultant (+)-albaconol $\mathbf{4 1}$ and (+)-neoalbaconol 37, respectively. In a stark contrast with the yahazunol isomer 24, the inhibitory effect of (+)-albaconol 41 against $R$. sola$n i$ decrease exponentially as the $\mathrm{EC}_{50}$ value increased to $>$ $150 \mu \mathrm{M}$. The high antifungal selectivity between $S$. sclerotiorum and $R$. solani may differentiate this natural product from the others in potential action mechanism and also provide a new orientation for the design of new chemical entities. The antifungal activity of $(+)$-neoalbaconol 37 against $S$. sclerotiorum reduced by half compared with compound 25. The subtle yet complex influence of the hydroxyl group on the biological outcome was also observed in the antiproliferative activity against HepG2 and MCF-7. Except for (+)-dictyvaric acid 34, all other four promising antifungal leads showed significant inhibitory effect against cancer cell lines HepG2 and MCF-7 with the $\mathrm{EC}_{50}$ values ranging from 10.08 to $16.04 \mu \mathrm{M}$, which verified over 3 -fold enhancement than that of $(+)$-yahazunol.

\begin{tabular}{|c|c|c|c|c|c|c|c|c|c|}
\hline \multirow{2}{*}{ Compd. } & \multicolumn{4}{|c|}{$\mathrm{EC}_{50}(\mu \mathrm{M})$ values of antifungal and antitumor activities } & \multicolumn{5}{|c|}{ Calculated properties } \\
\hline & S. sclerotiorum & R. solani & HepG2 & MCF-7 & MW & TPSA & CLogP & $\mathrm{Fsp}^{3}$ & $\mathrm{Cm}$ \\
\hline 4 & $>150$ & $>150$ & $>50$ & $>50$ & 332.5 & 60.69 & 5.328 & 0.714 & 290.04 \\
\hline 24 & 26.7 & 29.31 & 13.92 & 16.04 & 332.5 & 60.69 & 5.278 & 0.714 & 246.11 \\
\hline 25 & 15.19 & 41.67 & 10.16 & 11.91 & 332.5 & 60.69 & 5.328 & 0.714 & 290.04 \\
\hline 34 & 22.16 & 22.54 & $>50$ & $>50$ & 360.5 & 77.76 & 6.077 & 0.682 & 309.21 \\
\hline 37 & 40.38 & 35.16 & 11.09 & 11.32 & 346.5 & 60.69 & 5.777 & 0.727 & 252.53 \\
\hline 41 & 24.35 & $>150$ & 10.44 & 10.08 & 343.2 & 60.69 & 5.777 & 0.727 & 296.87 \\
\hline PC & 0.75 & 1.62 & 3.51 & 1.17 & & & & & \\
\hline
\end{tabular}

B. Predictive Targets for Yahazunol Related Isomers and Natural Products

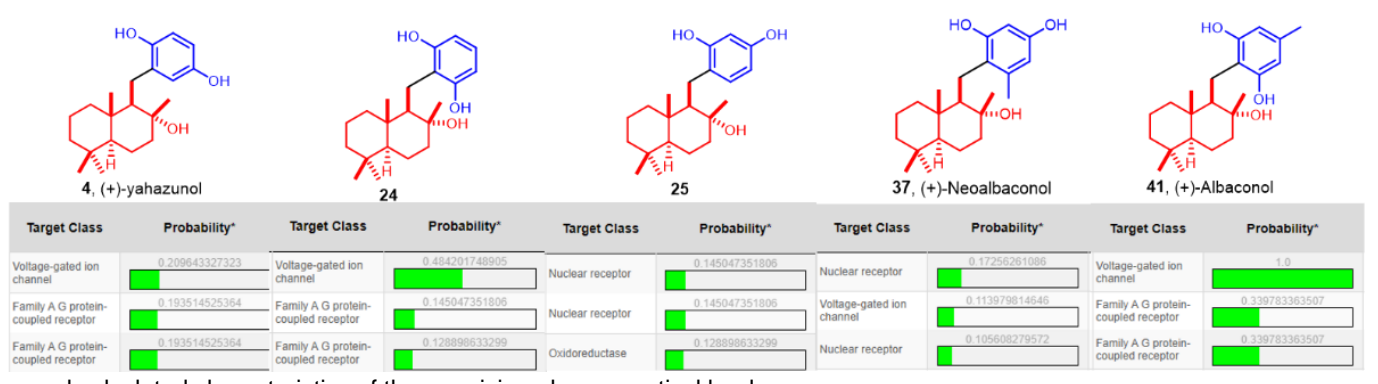

Figure 6 Bioactivities and calculated characteristics of the promising pharmaceutical leads.

Given the profound effect of the intrinsic characteristics on the biological performance, the metrics consisted of molecular weight (MW), calculated octanol-water partition coefficients (CLogP), and topological polar surface area (TPSA) were retrieved from ChemBioOffice (Figure 6A). The variation range of these metrics was very limited and the isomers (4 vs 24 and 25, 37 vs 41 ) have same values of MW, TPSA and Fsp3. The MW values and CLogP values of these compounds correlated well with the statistical analysis for agrochemical fungicides [43]. Increment of Fsp3 was attested to be beneficial for the success in the development of pharmaceuticals [44], and the selected new potential 
leads (Figure 6A) possessed an innate Csp3 hybridized drimane subunit as a significant contribute to this by improving Fsp3 to $>0.6$. The intrinsic complexity of the potent leads measured by Böttcher score was also calculated [45], manifesting the isomerization of yahazunol to compound $\mathbf{2 4}$ just by shifting the position of hydroxyl group on the phenyl ring can lead to significant differentiation in not only biological outcome but also the intrinsic complexity.

Inspired by the aforementioned big difference from isomerization, the potential targets of these pharmaceutically important natural products and their isomers were predicted through SwissTargetPrediction [46] and the predicted top 3 targets were listed in Figure 6B. Curiously, the yahazunol isomer 25 was speculated to interact with discrepant targets from that of yahazunol and another isomer 24. Meanwhile, the most probable macromolecular target of (+)neoalbaconol 37 was significant different from its isomer $(+)$-albaconol 41. These novelties may reinforce the value for further exploration.

\section{Conclusion}

In conclusion, drimane hydroquinones are structurally advantaged for biological exploration, but not very wellorganized for pharmaceutical development. With the prevalidated antifungal (+)-chromazunarol as a model, antifungal activity oriented divergent optimization was executed and facilitated by the scalable and facile Suzuki coupling. This is the first divergent optimization of the complex natural product chromazonarol in discovery science for new pharmaceutical leads. The phenolic hydroxyl group was demonstrated to be one inviolable requirement for antifungal effect. Bioactivity oriented simplication of $(+)$-chromazonarol led to the identification of yahazunol relevant natural products and unprecedented isomers as antifungal and antitumor agents. The first synthesis and antifungal profiles of (+)albaconol and (+)-neoalbaconol, and the first biological profiles of (+)-dictyvaric acid were disclosed. Buoyed by these success, the synthetic approaches to (+)-8-epipuupehedione and the promising pelorol analogue were obviously improved. Through the synergistic interaction of the programmable synthesis and bioactivity-guided screening, the structure-activity relationship of yahazunol relevant (non)-natural products was delineated. The probable macromolecular targets were also estimated and the resultant differentiation may deliver new information about the resident biological potential. This will add incentive to search for additional cryptic drimane hyhdroquinones, targeting at creating opportunities for addressing new biological issues.

Acknowledgments This work was financially supported by National Natural Science Foundation of China (No.s 21772094, 21977049), and Natural Science Foundation of Jiangsu Province (BK20191306). Author contributions
Author contributions S. Li conceived this work. X. Wang, N. Hu and W. Kong conducted all experimental work and provided the results. X. Wang and $\mathrm{S}$. Li analyzed the data and wrote the manuscript.

Conflict of interest The authors declare that they have no conflict of interest.

\section{Table of Contents graphic}

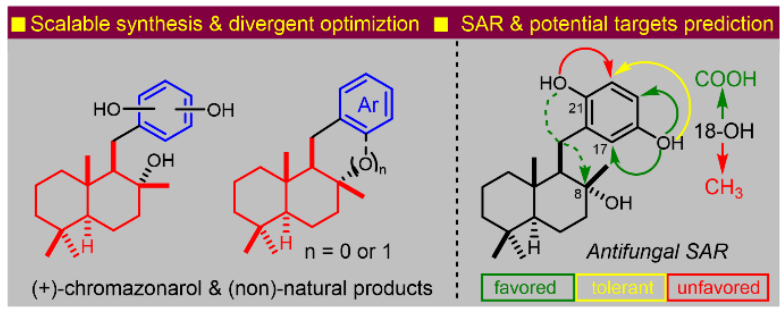

1 Sparks TC, Hahn DR, Garizi NV. Pest Manag Sci, 2017, 73: 700715

2 Newman DJ, Cragg GM. J Nat Prod, 2020, 83: 770-803

3 Porras G, Chassagne F, Lyles JT, Marquez L, Dettweiler M, Salam AM, Samarakoon T, Shabih S, Farrokhi DR, Quave CL. Chem Rev, 2020 ,

4 Truax NJ, Romo D. Nat Prod Rep, 2020, 37: 1436-1453

$5 \quad$ Wu Z-C, Boger DL. Nat Prod Rep, 2020, 37: 1511-1531

6 Shan W-G, Ying Y-M, Ma L-F, Zhan Z-J. Studies in Natural Products Chemistry, 2015, 45, Chapter 6: 147-215

7 Fenical W, Sims JJ, Squatrito D, Wing RM, Radlick P. J Org Chem, 1973, 38: 2383-2386

8 Cimino G, De Stefano S, Minale L. Experientia, 1975, 31: 11171118

9 Prawat H, Mahidol C, Kaweetripob W, Wittayalai S, Ruchirawat S. Tetrahedron, 2012, 68: 6881-6886

10 Fenical W, McConnell O. Experientia, 1975, 31: 1004-1005

11 Ishibashi F, Sato S, Sakai K, Hirao S, Kuwano K. Bioscience, Biotechnology, and Biochemistry, 2013, 77: 1120-1122

12 Kumagai M, Nishikawa K, Matsuura H, Umezawa T, Matsuda F, Okino T. Molecules, 2018, 23: 1214/1211-1214/1218

13 Barrero AF, Alvarez-Manzaneda EJ, Herrador MM, Chahboun R, Galera P. Bioorganic \& Medicinal Chemistry Letters, 1999, 9: 23252328

14 Castro ME, González-Iriarte M, Barrero AF, Salvador-Tormo N, Muñoz-Chápuli R, Medina MÁ, Quesada AR. International Journal of Cancer, 2004, 110: 31-38

15 Mogi T, Kawakami T, Arai H, Igarashi Y, Matsushita K, Mori M, Shiomi K, Ōmura S, Harada S, Kita K. J Biochem 2009, 146: 383387

16 Li S, Li D, Xiao T, Zhang S, Song Z, Ma H. J Agric Food Chem, 2016, 64: 8927-8934

17 Zhang L, Li W, Xiao T, Song Z, Csuk R, Li S. J Agric Food Chem, 2018, 66: 8957-8965

18 Wang G, Cui P, Bai H, Wei S, Li S. J Agric Food Chem 2019, 67: 11901-11910

19 Li D, Zhang S, Song Z, Wang G, Li S. Eur J Med Chem, 2017, 136: 114-121

20 Zhang S, Li D, Song Z, Zang C, Zhang L, Song X, Li S. J Agric Food Chem, 2017, 65: 9013-9021

21 Li D, Zhang S, Song Z, Li W, Zhu F, Zhang J, Li S. Eur J Med Chem, 2018, 143: 558-567

22 Zhang S, Wang X, Hao J, Li D, Csuk R, Li S. J Nat Prod 2018, 81: 2010-2017

23 Wang H-S, Li H-J, Zhang Z-G, Wu Y-C. Eur J Org Chem, 2018, 2018: 915-925

24 Alvarez-Manzaneda EJ, Chahboun R, Cabrera E, Alvarez E, Haidour A, Ramos JM, Alvarez-Manzaneda R, Hmamouchi M, Bouanou H. $J$ Org Chem, 2007, 72: 3332-3339 
Rosen BR, Simke LR, Thuy-Boun PS, Dixon DD, Yu J-Q, Baran PS. Angew Chem, Int Ed, 2013, 52: 7317-7320

26 Dixon DD, Lockner JW, Zhou Q, Baran PS. J Am Chem Soc, 2012, 134: 8432-8435

27 Armstrong V, Barrero AF, Alvarez-Manzaneda EJ, Cortes M, Sepulveda B. J Nat Prod, 2003, 66: 1382-1383

28 F.Barrero A, Alvarez-Manzaneda EJ, RachidChahboun, M.CortésbV.Armstrong. Tetrahedron, 1999, 55: 15181-15208

29 F.Barrero A, J.Alvarez-Manzaned E, Chahboun R. Tetrahedron Lett, 1997, 38: 2325-2328

30 Maiti S, Sengupta S, Giri C, Achari B, Banerjee AK. Tetrahedron Lett, 2001, 42: 2389-2391

31 Ishibashi H, Ishihara K, Yamamoto H. J Am Chem Soc, 2004, 126: 11122-11123

32 Dethe DH, Murhade GM, Dherange BD, Sau SK. Eur J Org Chem, 2017, 2017: 1143-1150

33 Quideau S, Lebon M, Lamidey A-M. Org Lett, 2002, 4: 3975-3978

34 Fernandez A, Alvarez E, Alvarez-Manzaneda R, Chahboun R, Alvarez-Manzaneda E. Chem Commun 2014, 50: 13100-13102

35 Meimetis LG, Nodwell M, Yang L, Wang X, Wu J, Harwig C, Stenton GR, MacKenzie LF, MacRury T, Patrick BO, Ming-Lum A, Ong CJ, Krystal G, Mui ALF, Andersen RJ. Eur J Org Chem, 2012, 2012: 5195-5207, S5195/5191-S5195/5164

36 Song FH, Fan X, Xu XL, Zhao JL, Han LJ, Shi JG. J Asian Nat Prod Res, 2005, 7: 777-781

37 Chen Q, Liu M-H, Yangl W-M, Zhang Y-1, Wang L, Liu J-K. Planta Medica, 2004, 70: 792-796

38 Liu Q, Shu X, Sun A, Sun Q, Zhang C, An H, Liu J, Cao X. Int Immunopharmacol, 2008, 8: 1103-1111

39 Liu Q, Shu X, Wang L, Sun A, Liu J, Cao X. Cell Mol Immunol, 2008, 5: 271-278

40 Deng Q, Yu X, Xiao L, Hu Z, Luo X, Tao Y, Yang L, Liu X, Chen H, Ding Z, Feng T, Tang Y, Weng X, Gao J, Yi W, Bode AM, Dong Z, Liu J, Cao Y. Cell Death Dis, 2013, 4: e804

41 Wang J, Li W, Wang B, Hu B, Jiang H, Lai B, Li N, Cheng M. Curr Pharmacol Rep, 2017, 3: 184-195

42 Yu X, Li W, Deng Q, You S, Liu H, Peng S, Liu X, Lu J, Luo X, Yang L, Tang M, Weng X, Yi W, Liu W, Wu S, Ding Z, Feng T, Zhou J, Fan J, Bode AM, Dong Z, Liu J, Cao Y. Mol Carcinog, 2017, 56: $1414-1426$

43 Rao H, Huangfu C, Wang Y, Wang X, Tang T, Zeng X, Li Z, Chen Y. Mol Inf, 2015, 34: 331-338

44 Lovering F. Med Chem Commun, 2013, 4: 515-519

45 Böttcher T. J Chem Inf Model, 2016, 56: 462-470

46 Daina A, Michielin O, Zoete V. Nucleic Acids Res, 2019, 47: W357W364 